\title{
Exploring Controls on Tropical Cyclone Count through the Geography of Environmental Favorability
}

\author{
Kimberly A. HoOgewind ${ }^{a}$ AND DANIEl R. Chavas \\ Department of Earth, Atmospheric, and Planetary Sciences, Purdue University, West Lafayette, Indiana \\ BENJAMIN A. SCHENKEL \\ School of Meteorology, University of Oklahoma, and Cooperative Institute for Mesoscale Meteorological Studies, \\ Norman, Oklahoma \\ MORGAN E O’NeILL \\ Department of Earth System Science, Stanford University, Stanford, California
}

(Manuscript received 14 December 2018, in final form 11 November 2019)

\begin{abstract}
Globally, on the order of 100 tropical cyclones (TCs) occur annually, yet the processes that control this number remain unknown. Here we test a simple hypothesis that this number is limited by the geography of thermodynamic environments favorable for TC formation and maintenance. First, climatologies of TC potential intensity and environmental ventilation are created from reanalyses and are used in conjunction with historical TC data to define the spatiotemporal geography of favorable environments. Based on a range of predefined separation distances, the geographic domain of environmental favorability is populated with randomly placed TCs assuming a fixed minimum separation distance to achieve a maximum daily packing density of storms. Inclusion of a fixed storm duration yields an annual "maximum potential genesis" (MPG) rate, which is found to be an order of magnitude larger than the observed rate on Earth. The mean daily packing density captures the seasonal cycle reasonably well for both the Northern and Southern Hemispheres, though it substantially overestimates TC counts outside of each hemisphere's active seasons. Interannual variability in MPG is relatively small and is poorly correlated with annual storm count globally and across basins, though modest positive correlations are found in the North Atlantic and east Pacific basins. Overall, the spatiotemporal distribution of favorable environmental conditions appears to strongly modulate the seasonal cycle of TCs, which certainly strongly influences the TC climatology, though it does not explicitly constrain the global annual TC count. Our methodology provides the first estimate of an upper bound for annual TC frequency and outlines a framework for assessing how local and large-scale factors may act to limit global TC count below the maximum potential values found here.
\end{abstract}

\section{Introduction}

Each year, $\sim O(100)$ tropical cyclones (TCs) form globally (e.g., Emanuel and Nolan 2004; Ramsay 2017). However, it is not well understood what processes govern this number or why this number is 100 , rather than 10

\footnotetext{
${ }^{\text {a }}$ Current affiliation: Cooperative Institute for Mesoscale Meteorological Studies, University of Oklahoma, and NOAA/OAR/National Severe Storms Laboratory, Norman, Oklahoma.
}

Corresponding author: Kimberly A. Hoogewind, kimberly. hoogewind@noaa.gov or 1000. What controls the global annual rate of TC formation? It has been proposed that this number may be set by some internal negative climate feedback (Emanuel and Nolan 2004), which may include negative radiative feedbacks associated with the drying of the free troposphere in the presence of higher convective aggregation (Khairoutdinov and Emanuel 2010; Wing and Emanuel 2014; Bony et al. 2015), oceanic feedbacks associated with mixing-induced sea surface cooling beneath storms (Vincent et al. 2014) and the subsequent cooling and drying of the boundary layer it may induce (Schenkel and Hart 2015), or other unknown internal dynamical or thermodynamic feedbacks within the 
system. If no such feedback exists, then we might expect this number to be set by the geography and seasonality of environmental favorability. The latter is perhaps the simplest hypothesis, but has yet to be tested and is the topic of this manuscript.

The global climatology of TCs has been studied extensively (e.g., Gray 1968, 1979; Ramsay 2017), along with the environmental parameters conducive for TC genesis and maintenance. Gray (1979) identified six parameters to be necessary, though insufficient, conditions for TC genesis: adequate planetary vorticity, enhanced low-level relative vorticity, conditional instability, elevated midlevel relative humidity, weak vertical wind shear, and warm sea surface temperatures exceeding $26^{\circ} \mathrm{C}$. Later empirical studies, largely based upon these aforementioned parameters outlined by Gray, have combined dynamic and thermodynamic parameters statistically into a genesis potential index (GPI), taking on various forms (e.g., Royer et al. 1998; DeMaria et al. 2001; Emanuel and Nolan 2004; Yokoi and Takayabu 2009; Emanuel 2010; Tippett et al. 2011; McGauley and Nolan 2011). Menkes et al. (2012) provides an overview and intercomparison of four of these tropical cyclogenesis indices, and found that differences between indices can be quite significant, though each could reasonably capture the seasonality of TC genesis. Several studies have also linked GPIs to modes of internal climate variability such as El Niño-Southern Oscillation (ENSO; e.g., Camargo et al. 2007b; Menkes et al. 2012), the Madden Julian oscillation (MJO; Camargo et al. 2009; Wang and Moon 2017), and the nonlinear interaction between ENSO and MJO and their impacts on TC genesis ( $\mathrm{Li}$ et al. 2012). In addition, these indices have been used to evaluate potential impacts that climate change may have upon TCs from global climate model projections (Camargo et al. 2007a; Caron and Jones 2008; Vecchi and Soden 2007; Chauvin and Royer 2010; Kim et al. 2011; Bruyère et al. 2012; Murakami and Wang 2010; Camargo et al. 2014; Song et al. 2015).

As described by Emanuel and Nolan (2004), the GPI incorporates midlevel relative humidity, low-level absolute vorticity, vertical wind shear, and the maximum potential intensity $\left(u_{\mathrm{PI}}\right)$, where $u_{\mathrm{PI}}$ replaces earlier use of an SST threshold as a thermodynamic predictor (Bister and Emanuel 2002). Maximum potential intensity describes the theoretical maximum wind speed that could be obtained by a TC assuming gradient wind balance and considering the local background thermodynamic environment in which it is embedded. Emanuel (2010) made further modifications to this GPI, replacing the midlevel relative humidity with nondimensional saturation entropy deficit. While many modifications have been made upon previous GPIs, these indices remain empirical in nature, and the statistical fitting of parameters are dependent upon the historical TC climatology. Thus, their application to future climate, and even individual ocean basins, may be problematic, and an index with a theoretical basis is desirable.

Formulations of GPI began to evolve from primarily statistical work toward physics-based quantities rooted in theory, and subsequent modifications have tended toward a physical quantity known as the ventilation index (VI; Tang and Emanuel 2012). VI is a nondimensional quantity that incorporates very similar variables as previous GPIs to quantify environmental conditions that are favorable for both TC genesis and intensification. Based upon a theoretical framework rather than empirical estimation, VI captures the detrimental thermodynamic effect of vertical wind shear on a TC via the import of midlevel environmental dry air into the TC core, a process called "ventilation." Specifically, VI is formulated as the product of environmental vertical wind shear and nondimensional midlevel entropy deficit, normalized by $u_{\mathrm{PI}}$, which Tang and Camargo (2014) describe as "a ratio of 'antifuel' to 'fuel' terms." Chavas (2017) rederived VI in terms of a power budget equation and extended the application to the case of capped surface entropy fluxes. Hence, VI may be considered a measure of environmental "resistance" to TC activity (Korty et al. 2017), and thus more favorable environments are associated with lower VI values. It is notable that recent versions of genesis indices (Camargo et al. 2014) show convergence toward those variables used within VI. Overall, VI has been shown to have strong influence upon the global TC climatology; anomalously low values of VI can be a skillful indicator for both TC genesis potential and intensification (Tang and Emanuel 2012). Indeed, Tang and Camargo (2014) utilized VI to investigate changes in the frequency of days supportive of TC genesis and rapid intensification by the end of the twenty-first century due to climate change. Korty et al. (2017) also used this index to evaluate how TC environments and activity change in experiments with very high $\mathrm{CO}_{2}$ concentrations.

While useful tools for researchers and forecasters, all genesis indices, VI included, have known biases. Past work has identified mismatches between genesis indices and actual TC genesis, though this result will depend on the choice of variables (McGauley and Nolan 2011; Menkes et al. 2012). A portion of the discrepancies may be attributed to the spatial distribution of the genesis indices. For example, Daloz and Camargo (2018) note the spatial distribution of many genesis indices tend to have a greater meridional extent that abuts the equator. Furthermore, limitations of GPIs also arise as each index necessarily requires a preexisting disturbance for 
the development of a TC. A priori knowledge of mechanisms that may initiate tropical disturbances, such as easterly waves (Thorncroft and Hodges 2001), the intertropical convergence zone (ITCZ; Ferreira and Schubert 1997; Yokota et al. 2015), and convectively coupled equatorial waves (e.g., Frank and Roundy 2006; Wu and Takahashi 2018) are likely pertinent factors toward determining genesis potential. Without accounting for storm seeding, favorable environments may otherwise be unrealized by TC formation. Nonetheless, such indices have been very valuable in relating TC activity to larger-scale environmental conditions in which a TC could in principle exist across climate states (e.g., Korty et al. 2017; Daloz and Camargo 2018), which is of direct interest to the topic at hand.

Climate models have been used to dynamically generate TC climatological frequencies with improving success, especially as model resolution improves (e.g., Walsh et al. 2016). Projections of future TC climatology under climate change generally point to a reduction in TCs; however, the consensus is not unanimous and basin specific projections vary considerably (Walsh et al. 2016). Results can be sensitive to model resolution, climate experiment and scenarios, and detection and tracking schemes used to identify TCs (Camargo and Wing 2016; Walsh et al. 2016). A physical mechanism responsible for the projected decline in global TC frequency by many models has yet to be identified, though possible explanations are emerging (Knutson et al. 2019). Despite this, the lack of an extant climate theory for TC genesis frequency introduces uncertainty, and confidence in projected TC frequency is assessed as "low to medium" by the majority of authors in Knutson et al. (2019). The disparity in global TC estimates by dynamical models further motivates this study. The diversity of estimates by physical models may potentially arise from the representation of processes internal to genesis itself or due to variations in the larger-scale thermodynamic parameters that govern environmental favorability for genesis. Here we examine the latter.

The present study investigates the question of what controls the global annual rate of TC formation by testing perhaps the simplest possible hypothesis: the global TC count is limited by the geography of environmental favorability. A similar spirit underlies the recent work of Tory et al. (2018), which examined seasonally averaged quantities of several variables to evaluate the environmental geographic boundaries for TC formation, with a focus on $u_{\mathrm{PI}}$, vertical wind shear, midlevel relative humidity, and a composite parameter of the ratio of $850 \mathrm{hPa}$ absolute vorticity to the meridionally gradient of absolute vorticity at $700 \mathrm{hPa}$. Here, we look to move one step further and quantify the extent to which the annual TC frequency in the present climate is limited by the spatiotemporal distribution of favorable environmental conditions, using established measures of dynamic and thermodynamic favorability. This work combines reanalysis-based datasets of potential intensity and environmental ventilation to define favorable regions capable of supporting TCs to explore our hypothesis that the geography of environmental favorability may constrain the annual TC count. This approach effectively assumes zero feedback of the storms themselves on the climate system and the geographical variation of favorable environmental conditions generated within the system, though potential intensity and its inclusion in VI may implicitly account for such feedbacks (Hart et al. 2007). Furthermore, we do not explicitly account for the presence of a preexisting disturbance to seed tropical cyclogenesis. Finally, this work will attempt to quantify the environmentally constrained upper bound on TC count in the present climate, including a simple estimate of how many more TCs could theoretically fit onto Earth each year.

The organization of the manuscript is as follows. Section 2 describes the data and methods used, and results are presented in section 3a. A discussion of our results are outlined in section 4 , followed by concluding remarks and suggestions for future work.

\section{Data and methods}

\section{a. Data}

Observed tropical cyclone data (1979-2016) are obtained from a subset of the International Best Track Archive for Climate Stewardship (IBTrACS) version 3, revision 10 (Knapp et al. 2010). Specifically, we utilize data provided by a combination of the U.S. National Hurricane Center and the Joint Typhoon Warning Center (NHC+JTWC). The impact of choosing NHC+JTWC versus the IBTrACS subset from the World Meteorological Organization (WMO) has been previously discussed by Schreck et al. (2014). In this study, only tropical cyclones that obtained tropical storm (TS) classification ( $\geq 34 \mathrm{kt}$ ) $\left(1 \mathrm{kt} \approx 0.5144 \mathrm{~m} \mathrm{~s}^{-1}\right)$ during their life cycle are considered (e.g., Ramsay 2017), and TC genesis is defined as the first 6-h data point in the best track data for those TCs reaching TS intensity. For deriving environmental parameters, as in Tang and Emanuel (2012), the European Centre for Medium-Range Weather Forecasts (ECMWF) interim reanalysis (ERA-Interim, hereafter ERA-I) serves as the source data. ERA-I is a 6-h gridded $\left(\sim 0.7^{\circ} \times 0.7^{\circ}\right.$ latitude by longitude $)$ global atmospheric reanalysis produced by the ECMWF (Dee et al. 2011). Vertical profiles of temperature, humidity, and wind, 


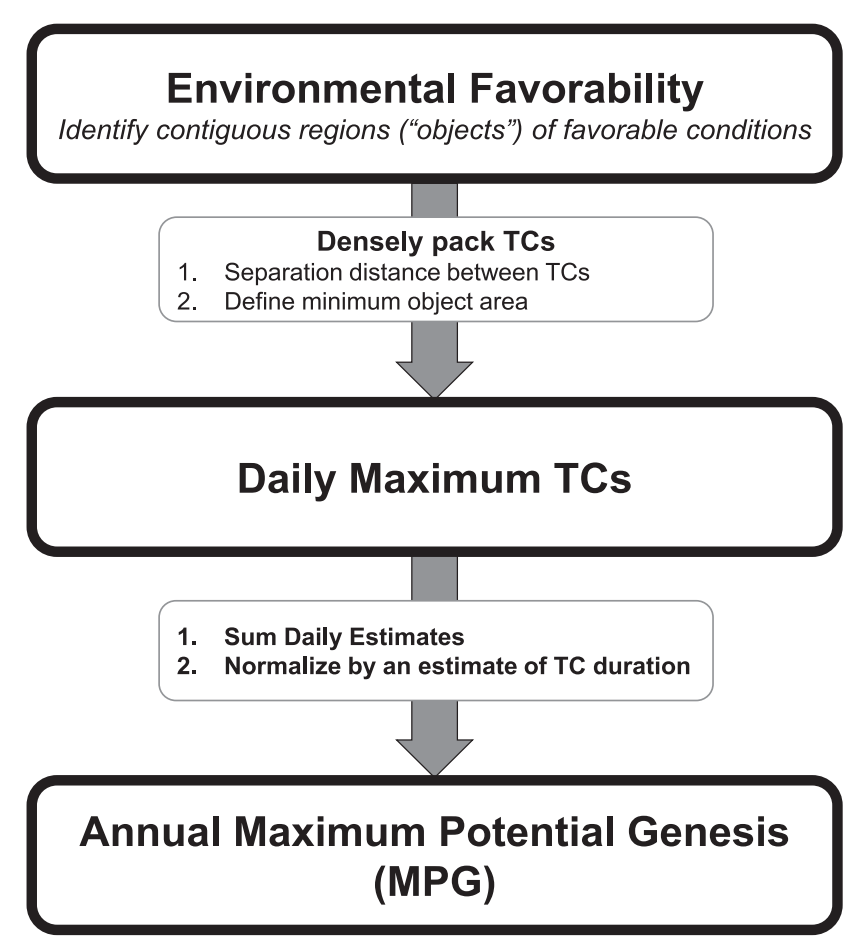

FIG. 1. Schematic demonstrating the process of arriving at an annual maximum potential genesis (MPG).

as well as surface pressure and sea surface temperature from the ERA-I, are obtained from the Research Data Archive (RDA) at the National Center for Atmospheric Research (NCAR; ECMWF 2009) for the period 19792016. These fields are used to compute relevant the TCspecific environmental parameters discussed in the next subsection.

\section{b. Methods}

Here we present a method to produce a first-order estimate of the annual maximum potential genesis (MPG); a schematic for this general process is demonstrated in Fig. 1. The identification of favorable environmental conditions capable of supporting TCs on any given day provides the initial foundation to arrive at an estimate for MPG. Subsequently, an evaluation of the maximum number of daily TCs that could theoretically exist is derived using a packing procedure to randomly populate the regions of favorability with TCs. This procedure requires the specification of a storm separation distance, and perhaps, a minimum area size of favorability for computation. Upon repeating this process for each day of the year, an estimate for MPG may be made by summing the daily maximum TC values and normalizing by an estimate for a reasonable TC lifetime duration. Each of these steps are outlined in more detail in the following subsections.

\section{1) DEFINING ENVIRONMENTAL FAVORABILITY}

Environmental favorability for the formation of TCs is herein defined by the combination of both thermodynamic and dynamic factors on a daily basis. As discussed earlier, we seek a minimal number of parameters that possess both strong theoretical grounding as well as observational utility. First, we utilize the VI (Tang and Emanuel 2012), defined as

$$
\mathrm{VI}=\frac{u_{\text {shear }} \chi_{m}}{u_{\mathrm{PI}}},
$$

where $u_{\text {shear }}$ represents the magnitude of the vector wind difference between 850 and $200 \mathrm{hPa}, \chi_{m}$ the nondimensional midlevel $(600 \mathrm{hPa})$ entropy deficit, and $u_{\mathrm{PI}}$ is the maximum potential intensity $\left(\mathrm{m} \mathrm{s}^{-1}\right.$; Bister and Emanuel 2002). The nondimensional midlevel entropy deficit $\left(\chi_{m}\right)$ is defined as in Eq. (2) of Tang and Emanuel (2012):

$$
\chi_{m}=\left(\frac{s_{m}^{*}-s_{m}}{s_{\mathrm{SST}}^{*}-s_{b}}\right)
$$

where $\chi_{m}$ represents the ratio of the difference between the saturation entropy at $600 \mathrm{hPa}$ in the inner core of the $\mathrm{TC}\left(s_{m}^{*}\right)$ and the environmental entropy at $600 \mathrm{hPa}\left(s_{m}\right)$, and the deviation of the entropy of the boundary layer $\left(s_{b}\right)$ from the sea surface temperature saturation entropy 


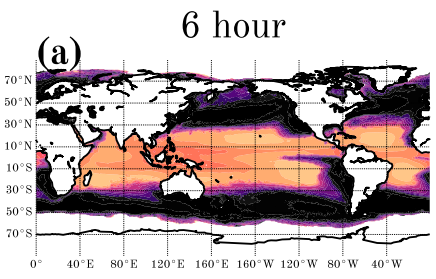

48 hour
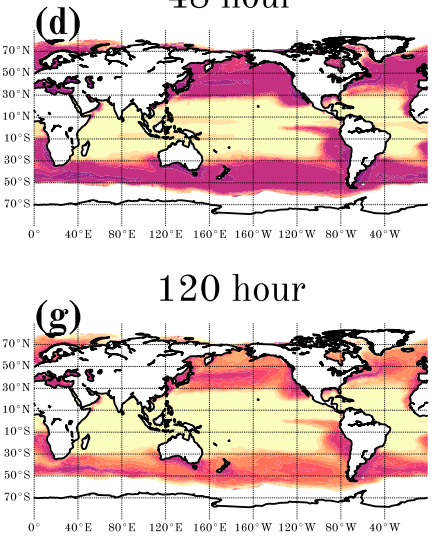

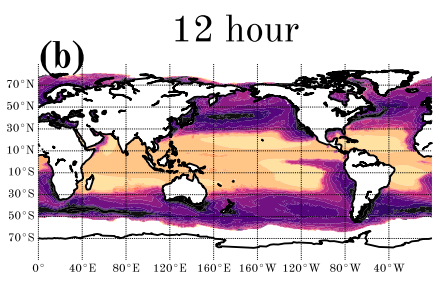

72 hour

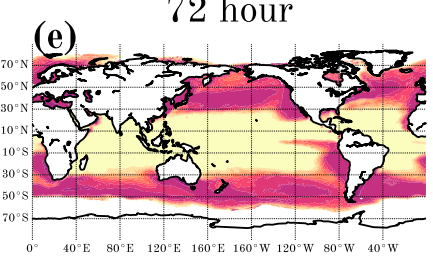

168 hour

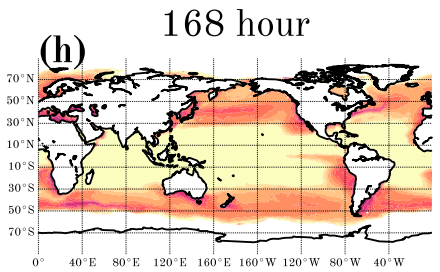

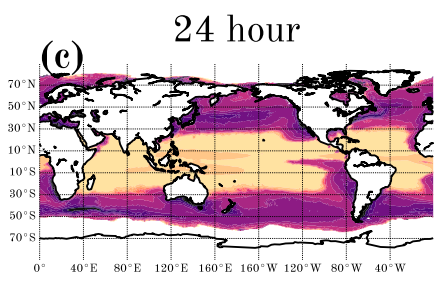

96 hour

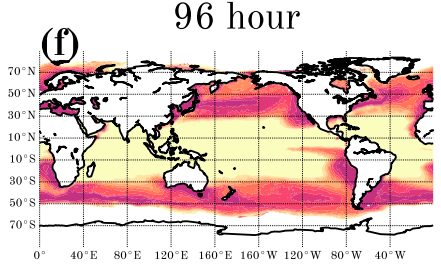

240 hour

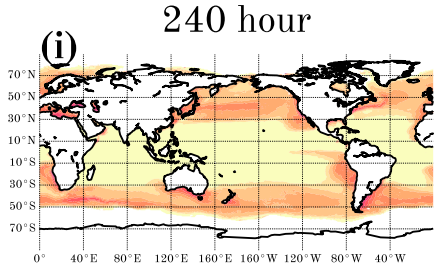

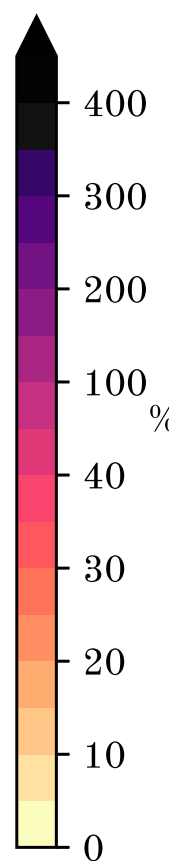

FIG. 2. Mean absolute departure from the annual climatological mean of VI, expressed as a percentage, for the period 1979-2016. A moving average filter was first applied to compute (b) 12, (c) 24, (d) 48, (e) 72, (f) 96, (g) 120, (g) 168, and (j) 240 h means from the ERA-I reanalysis 6-hourly data prior to differencing.

$\left(s_{\mathrm{SST}}^{*}\right)$. The maximum potential intensity $\left(u_{\mathrm{PI}}\right)$ is calculated using the algorithm of Bister and Emanuel (2002) under pseudoadiabatic assumptions, with the value for the ratio of the exchange coefficient for enthalpy $\left(C_{k}\right)$ to the drag coefficient $\left(C_{d}\right)$ set to 0.7 . The ventilation index incorporates both thermodynamic and dynamic quantities, and captures the thermodynamic effect of wind shear, namely, that wind shear induces asymmetries in the wind field that import low entropy air from the environmental free troposphere into the storm inner core. Second, the $850-\mathrm{hPa}$ absolute vorticity $(\eta)$ is incorporated, which imposes the requirement of sufficient ambient vorticity available for the generation of the storm circulation; the combination of VI and $\eta$ is similar to existing GPI formulations (e.g., Emanuel and Nolan 2004; Emanuel 2010; Tippett et al. 2011). Diagnosing environmental favorability could use any alternative genesis index within this methodology, but we have chosen VI on physical and empirical grounds as previously noted.

Finally, a sea surface temperature (SST) criterion is introduced. While previous work has identified a statistically reasonable minimum SST of $\sim 26^{\circ} \mathrm{C}$ to support TCs in the current climate (e.g., Tory and Dare 2015), it has been shown observationally that this threshold has increased (Defforge and Merlis 2017) and is not suitable for application to future climate (Johnson and Xie 2010; McTaggart-Cowan et al. 2015). As a result, we incorporate a more conservative threshold of $22^{\circ} \mathrm{C}$ to ensure focus on disturbances that are tropical in origin. Low VI values are occasionally found at high latitudes in the Northern Hemisphere, and these transient conditions arise primarily due to enhanced $u_{\mathrm{PI}}$ due to the instability that develops when cold air flows over warmer water (Emanuel and Rotunno 1989; Holland 1997); the incorporation of an SST criterion thereby excludes highlatitude areas that may otherwise be favorable for subtropical and polar lows (Emanuel and Rotunno 1989).

To identify daily areas of favorability based on the aforementioned parameters, appropriate thresholds of each quantity are defined. These thresholds are derived from the distribution of daily mean quantities at the location of TC genesis from the ERA-I reanalysis. The nearest grid point in ERA-I to the genesis location is found for all TCs in the 1979-2016 period from IBTrACS; values within $100 \mathrm{~km}$ of this location are averaged. To remove the representation of the storm itself within the reanalysis data, values of VI and $\eta$ are extracted for several days prior to genesis, and thresholds are derived then from the average of the 95th and 5th percentiles of the VI and $\eta$ distributions 5-10 days prior to genesis, respectively. The variables are first computed at each 6-h time step from ERA-I and daily means are derived. While variability from 6-h time step to time step is evident, the average departure for VI, for example, is $\sim 10 \%-25 \%$ of its mean annual value in the tropical latitudes (Fig. 2a). Application of a moving average 
(a)

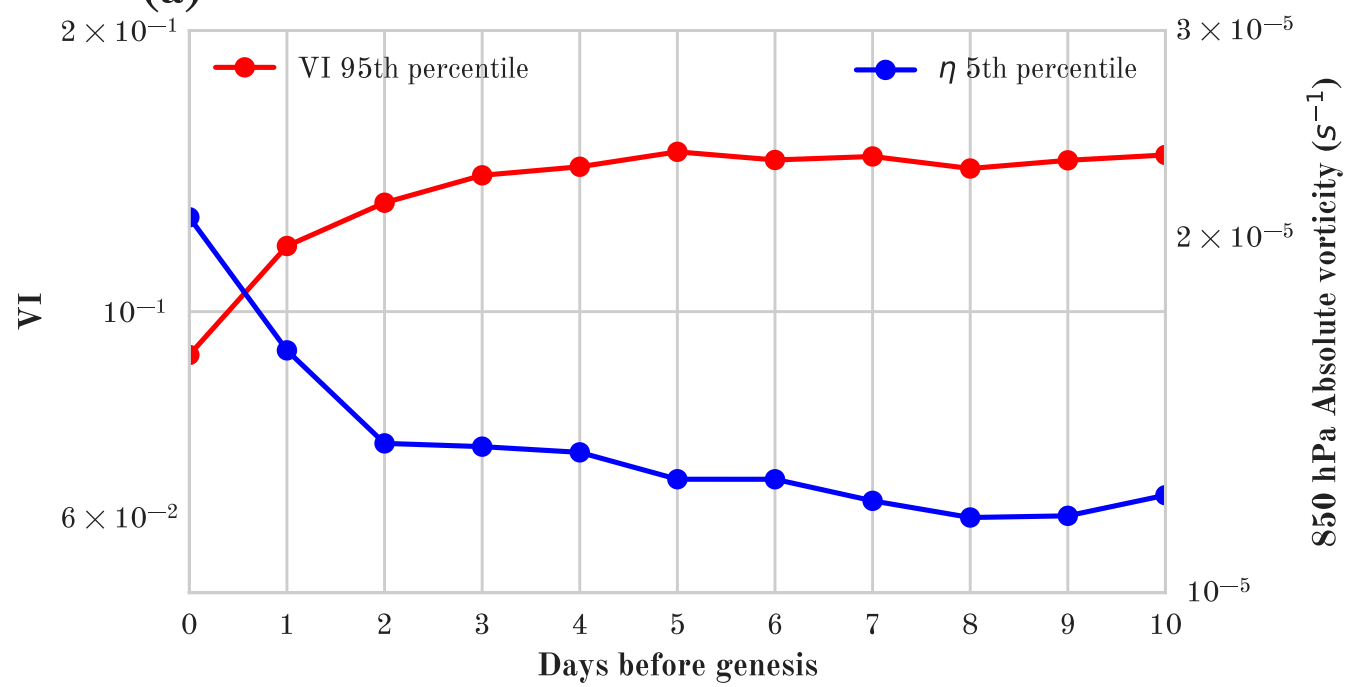

(b)

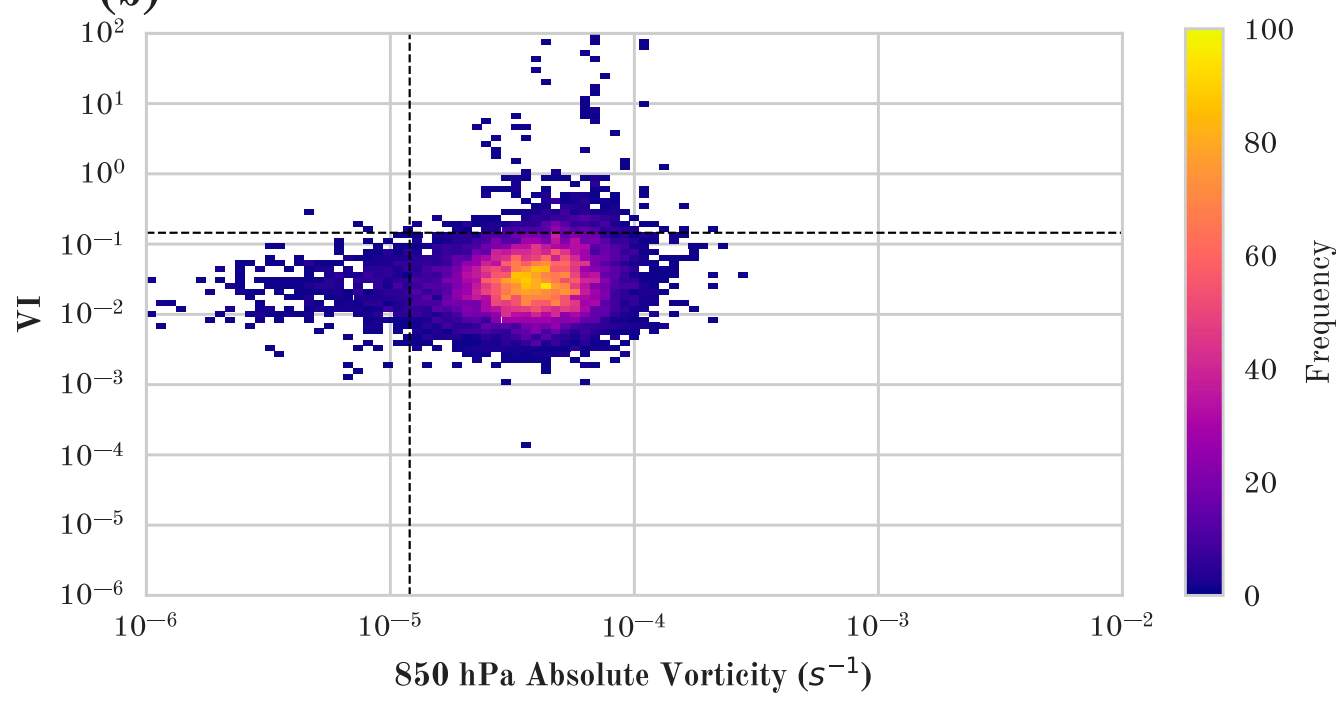

FIG. 3. (a) The 95th and 5th percentiles of mean VI and $\eta$ within $100 \mathrm{~km}$ of genesis locations at time of genesis and 10 days prior over the period 1979-2016. (b) Joint distribution of VI and $\eta$ 5-10 days prior to genesis. The thresholds for VI $(0.145)$ and $\eta\left(1.2 \times 10^{-5} \mathrm{~s}^{-1}\right)$ are represented by the horizontal and vertical black dashed lines.

filter for several time windows demonstrates that the variability declines (Figs. $2 \mathrm{~b}-\mathrm{i}$ ), such that VI variability is generally $5 \%-15 \%, 5 \%-10 \%$, and $<5 \%$ relative to climatology on 12-, 24-, and $\geq 48$-h time scales. Given these results, daily means are deemed suitable for our purposes, and follows work by Tang and Camargo (2014) that computed VI from daily mean data from global climate models as part of the Coupled Model Intercomparison Project, phase 5 (CMIP5). Moreover, one day represents a reasonable time scale for significant changes in tropical cyclone intensity both operationally (e.g., Kaplan et al. 2010) and theoretically (Emanuel 2012).
The thresholds for favorability used herein are 0.145 and $1.2 \times 10^{-5} \mathrm{~s}^{-1}$ for VI and $\eta$, respectively, taken as the average of the 95th and 5th percentiles 5-10 days prior to genesis (see Fig. 3a). A summary of thresholds for all parameters used to define environmental favorability may be found in Table 1 . A threshold of 0.145 for VI is close to the value of 0.1, which Tang and Emanuel (2012) found was supportive for a large portion of tropical disturbances to undergo TC genesis. The joint distribution of the two variables 5-10 days before genesis illustrates that a large majority $(\sim 91 \%)$ of storms form within conditions specified by our chosen thresholds (Fig. 3b). 
TABLE 1. Thresholds used for individual parameters (VI, $850 \mathrm{hPa} \eta$, and SST) to define environmental favorability in this study.

\begin{tabular}{lccc}
\hline \hline & VI & $\eta$ & SST \\
\hline Threshold & 0.145 & $1.2 \times 10^{6} \mathrm{~s}^{-1}$ & $22^{\circ} \mathrm{C}$ \\
\hline
\end{tabular}

\section{2) EstimATING ANNUAL MAXIMUM NUMBER OF TROPICAL CYCLONES}

A simple methodology is developed to produce a firstorder estimate of the maximum number of TCs that could hypothetically exist within regions of environmental favorability on a daily basis. In turn, this information is used to approximate the maximum number of TCs that could occur annually, provided we make the assumption that the daily regions of favorability may be densely packed with TCs within its domain. To arrive at an annual maximum TC count, the daily estimates are summed for the year, then normalized by a time scale representing a typical TC longevity, empirically estimated here by the median time duration (in days) that a TC exists within favorable conditions.

To define a maximum daily packing density, we first identify contiguous regions of favorability, or "objects." An object is defined where grid points within the ERA-I reanalysis data that meet our criteria for environmental favorability are connected to one another. As our estimate emerges naturally from the areal extent of environmental favorability, prior to performing this calculation, we first consider the size (surface area) distribution of our environmental objects. The distribution of those objects that historically were supportive of TC existence are highly skewed toward larger areas (Fig. 4a). The difference between all object areas and those that contained TC genesis locations or all TC points are statistically significantly different from one another at the $99 \%$ confidence level using the MannWhitney $U$ test (Mann and Whitney 1947). Indeed, the probability of TC genesis increases as the region size increases (Fig. 4b). Historically, 95\% of all TC genesis locations occurred within contiguous regions of environmental favorability that were greater than $\sim 5.7 \times$ $10^{6} \mathrm{~km}^{2}$ in area, while $95 \%$ of all TC track points occurred in areas greater than $\sim 1.7 \times 10^{6} \mathrm{~km}^{2}$. One possible explanation for such a result is that very small objects may simply be too small to fit a storm for an appreciable amount of time (or at all). Thus, in addition to using the all environmental objects of any size, we apply a minimum object area threshold and examine the sensitivity of our results to this choice of threshold.

Next, a separation distance between TC center locations is needed. Early work by Brand (1970) found that

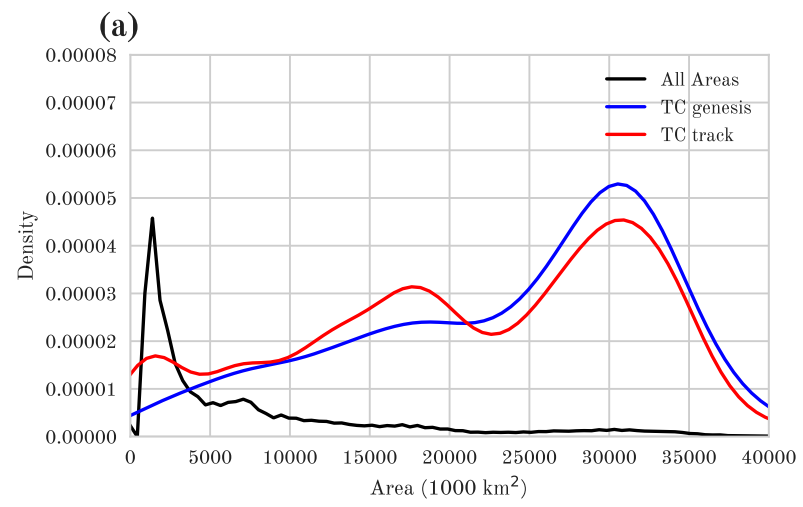

(b)

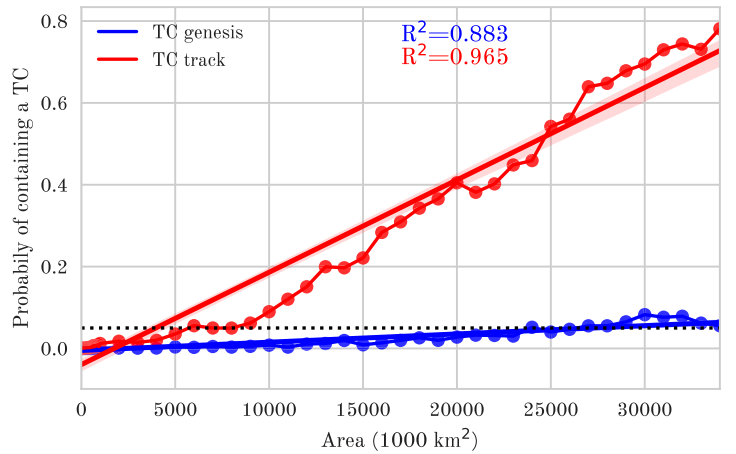

(c)

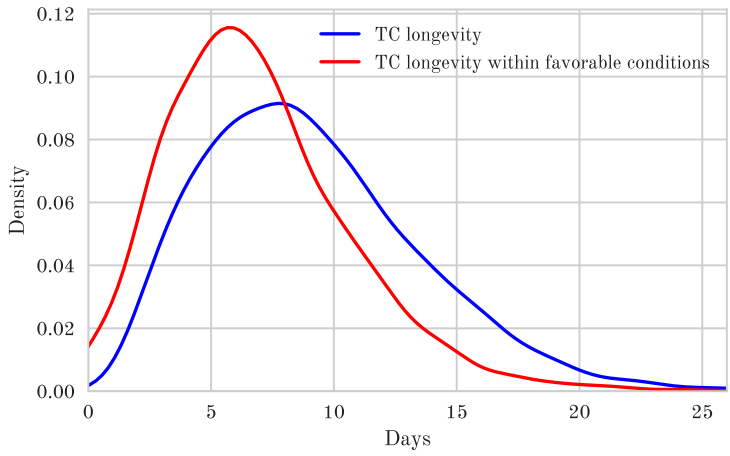

FIG. 4. (a) Distribution of the area of contiguous regions of environmental favorability, and those that contain TC genesis points or all TC points. (b) The probability of a region of environmental favorability to support TC genesis or maintenance based on area. (c) The distribution of TC life cycle longevity (in days) as well as the distribution of time that TCs existed within favorable environments. All distributions were computed for the period 1979-2016.

binary interaction between two storms in the western North Pacific (i.e., the Fujiwhara effect; Fujiwhara 1921) tended to occur when the separation distance between two storms fell below 750 nautical miles $(\mathrm{n} \mathrm{mi} ; 1 \mathrm{n} \mathrm{mi}=$ $1.852 \mathrm{~km})(\sim 1400 \mathrm{~km})$. Additionally, Schenkel (2016, 2017) examined the climatology of multiple tropical cyclone events and found median spacing distances within the range of approximately $1600-2000 \mathrm{~km}$ between new TC genesis locations and a preexisting TC, 


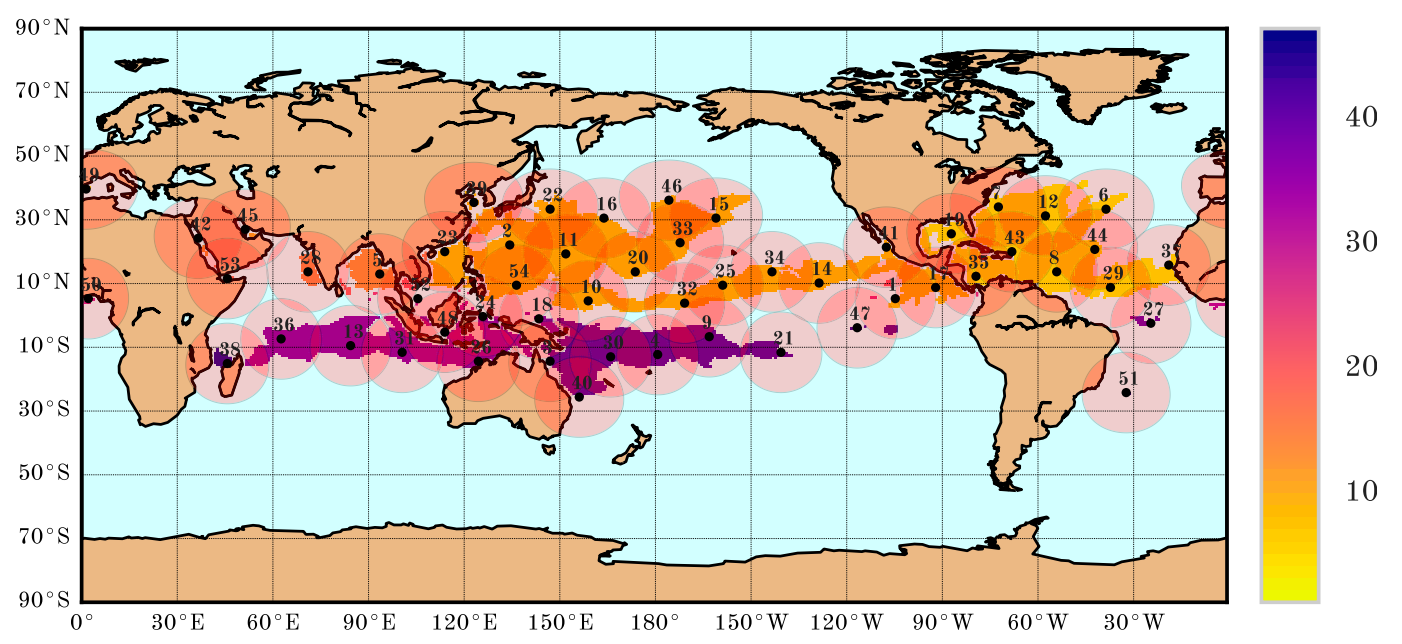

FIG. 5. An example of the random placement of storm centers (black circles) within unique contiguous regions (objects) of environmental favorability of any size for $21 \mathrm{Jul} 2005$. A separation distance of $1400 \mathrm{~km}$ is used as the radius to exclude grid points from future consideration after placement. Each contiguous area of environmental favorability is uniquely colored and numbered; additionally, each storm center is labeled with a number indicating the order of placement.

with results not differing significantly between basins. Based on these previous studies, we use a range of distances from 1400 to $2000 \mathrm{~km}$ every $200 \mathrm{~km}$ for our estimates, with the assumption that they are applicable globally. The Fujiwhara-based value of $1400 \mathrm{~km}$ represents a true physical lower bound because two storms cannot persist at smaller distances. In nature, it is likely that separation distances depend more strongly on the intrinsic length scales associated with the processes that generate disturbances, such as African easterly waves, monsoon troughs (Holland 1995; Thorncroft and Hodges 2001), and the breakdown of the ITCZ (Ferreira and Schubert 1997; Yokota et al. 2015), whose statistics will vary across basins (Schenkel 2016, 2017) and may further vary across climate states. Additionally, large-scale equatorial variability, such as the MJO and convectively coupled equatorial waves (Wheeler and Kiladis 1999) that suppress/enhance convection on regional scales and thus modify genesis favorability (Camargo et al. 2009; Klotzbach and Oliver 2015). Here we begin from the physical lower bound and then test the sensitivity of results to increasing separation distance; investigating the role of the true minimum separation distance and its underlying physics in nature is a fruitful direction for future work. However, we note that TC genesis may occur at a distance less than $1400 \mathrm{~km}$ from a preexisting $\mathrm{TC}$, but rarely occurs below a distance of $1000 \mathrm{~km}$ (Schenkel 2017). Additionally, multiple TCs may occur at distances larger than $2000 \mathrm{~km}$ (Krouse and Sobel 2010; Gao and Li 2011; Schenkel 2016, 2017). Furthermore, we do not take into account any temporal separation between TC genesis locations in this framework, nor do we account for feedbacks between the storms and the climate system that may alter the environmental favorability and its geographical configuration.

Finally, given the above constraints, we estimate the number of daily TCs by randomly arranging storms within the environmentally favorable domain. First, a grid point where the environmental conditions have been identified as favorable is randomly selected. This grid point serves as the hypothetical TC center location. Next, all grid points within a radius of the specified separation distance are then excluded from availability, and a new grid point is randomly chosen from those remaining. This process is iterated until no additional environmental grid points may be excluded. The total number of randomly arranged storms is then tallied for each day. This overall procedure is completed 100 times each day to provide a reasonable sample size for an estimated distribution of the maximum number of TCs per day that potentially could exist based on the geometry of environmental conditions.

Figure 5 provides an illustration of the random placement of storms for all contiguous regions of environmental favorability for 21 July 2005. Each object region is uniquely labeled with a different number and color. The location of the placed storm center is indicated by the black filled circles, and each is labeled with a number indicating the order in which it was placed. The shaded circles surrounding the storm centers are defined using a $1400 \mathrm{~km}$ separation distance to exclude environmental grid points from consideration for the next random placement of storm center. Circles may overlap; however, 
(a)

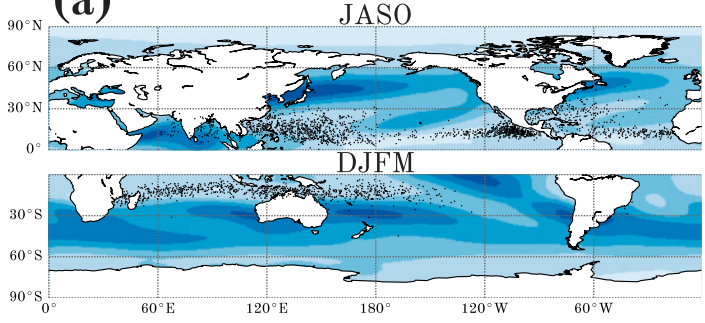

(b)

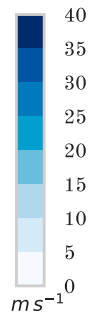

$$
m s^{-1}
$$

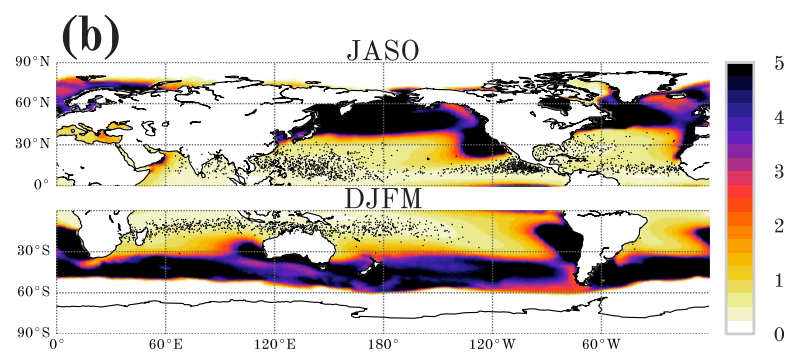

(d)

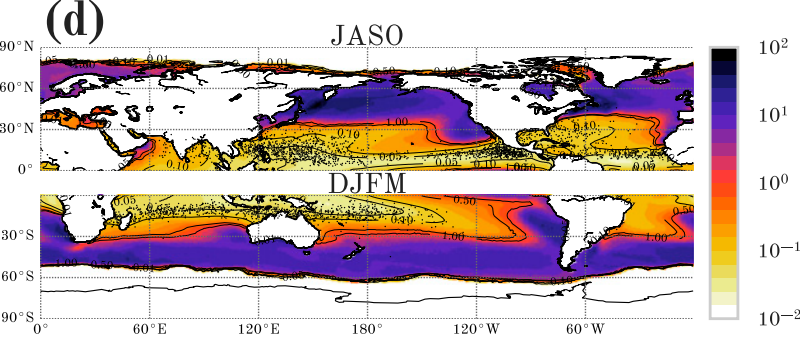

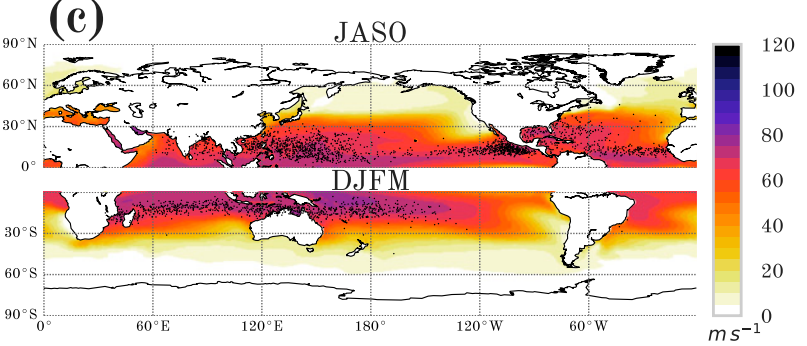
FIG. 6. Seasonal mean (a) 850-200-hPa bulk wind shear $\left(u_{\text {shear }}\right)\left(\mathrm{m} \mathrm{s}^{-1}\right)$, (b) 600-hPa nondimensional entropy, (c) maximum potential
intensity $\left(u_{\mathrm{PI}}\right)$, and (d) VI for the period 1979-2016. Black dots represent TC genesis locations during the seasonal time periods (1979-2016).

a storm center may not occur within another storm's circle. In this example (Fig. 5), there are 47 total environmental objects of which produced a random configuration of $54 \mathrm{TCs}$ within the domain. In comparison, applying the two area thresholds both reduce the number of environment objects to 5 , resulting in $\sim 46$ placed TCs.

The total annual number of TCs, hereafter the annual MPG, is then computed as follows:

$$
\mathrm{MPG}=\text { floor }\left(\frac{\sum_{i=1}^{365} N_{d}}{t_{d}}\right) \text {, }
$$

where $N_{d}$ (TCs per day) is the maximum number of TCs that could reside within the favorable environment objects on a daily basis indicated by our packing procedure, and $t_{d}$ represents the median TC life cycle duration (in days) within favorable environmental conditions. For the latter, based on the distribution of storm longevity within favorable conditions over the 1979-2016 period, the median longevity in terms of time spent within favorable conditions is found to be 6 days, despite a median total TC life cycle of 8 days (Fig. 4c). We thus use $t_{d}=6$ days in Eq. (3) for our estimates. The steps to arrive at MPG can be summarized as follows:

1) Identify contiguous areas (objects) of favorable environmental conditions.

2) Constrain environmental objects using a minimum area criterion (when applicable).

3) Compute the daily maximum number of TCs that could occupy objects for each day of the year using specified separation distances.
4) Calculate the annual MPG as in Eq. (3). This procedure sums the daily number of TCs (computed as in step 3 above) for each day, then normalizes this total value by a value for TC duration to arrive at an MPG count.

Our procedure is similar in spirit to the "genesis by random seeding" method of Emanuel et al. (2008), which randomly distributes genesis locations in space and time and then simulates the complete life cycle of each storm using physics-based models for storm intensity and motion. We have taken a simpler approach that similarly exploits the environmental physical controls of TC activity without explicit life cycle simulation, a method that is viable given that our focus is solely on the existence of a given storm at a given location without concern for its actual intensity nor its geographic provenance. Moreover, the methodology of Emanuel et al. (2008) requires the external specification of a global seeding rate that is tuned to the modern climate, and hence cannot be used to constrain global annual TC count. Here, our approach constrains the maximum potential genesis rate via the imposition of a minimum storm separation distance in combination with the geography of these environmental controls.

\section{Results}

\section{a. Environmental favorability}

The seasonal mean climatology (1979-2016) of VI and its components are shown in Figs. 6a-d. Seasons are defined as July-October for the Northern Hemisphere (NH) and December-March in the Southern Hemisphere (SH), 
TABLE 2. Seasonal mean values of VI and its components at genesis locations.

\begin{tabular}{lcc}
\hline \hline & JASO & DJFM \\
\hline$u_{\text {shear }}$ & $12.85 \mathrm{~m} \mathrm{~s}^{-1}$ & $12.69 \mathrm{~m} \mathrm{~s}^{-1}$ \\
$\chi_{m}$ & 0.41 & 0.57 \\
$u_{\text {PI }}$ & $67.26 \mathrm{~m} \mathrm{~s}^{-1}$ & $69.03 \mathrm{~m} \mathrm{~s}^{-1}$ \\
VI & 0.10 & 0.15 \\
\hline
\end{tabular}

comprising the most active months of the TC season in each respective hemisphere. The seasonal mean values for each hemisphere at genesis locations are listed in Table 2. Relative to the seasonal TC genesis locations, it is unsurprising that shear is lower in the tropical regions where TCs originate. The entropy deficit is also seasonally low in these areas while $u_{\mathrm{PI}}$ is high. In combination, VI values are anomalously low $(\leq 0.15)$ relative to higher latitudes. As noted in Tang and Emanuel (2012), VI is seasonally low near the equator despite the lack of TC genesis events, which motivated the inclusion of absolute vorticity (and implicitly the Coriolis parameter) into our favorability formulation.

Using these thresholds, daily regions of environmental favorability are derived from ERA-I. The annual climatology (1979-2016) of favorable days is depicted in Fig. 7a. Many regions in the tropics are shown to be nearly always favorable, with locations in both hemispheres of the western Pacific and also in the southeastern Indian Ocean shown to have favorable environmental conditions over $90 \%$ of the year. This result agrees with the previous findings of Menkes et al. (2012) that environmental indices tend to overestimate cyclogenesis during seasons that are otherwise unfavorable for TC formation. Overall, the dominant regions of TC activity are well captured by our environmental favorability diagnostic (Fig. 7a). However, there exists significant regional variability in the occurrence of actual storms within these environments. Indeed, the conditional probability of TC genesis given the presence of a favorable environment (Fig. 7b; calculated on a coarsened $5^{\circ} \times 5^{\circ}$ latitude/longitude grid to relax the spatial requirement for matches between gridded environmental estimates and TC track point values) indicates that the eastern North Pacific basin is climatologically most productive in terms of TC production, despite having fewer days of favorability relative to the aforementioned regions with maximum frequency of favorable conditions. A similar result is presented in Fig. 7c, which represents conditional probability of a TC at any point in its life cycle. Schenkel (2016) notes that the large-scale environment in the eastern North Pacific (EPAC) may be preconditioned for multiple TC events. Moreover, many of the regions with the most frequent environmental favorability do not produce TCs as effectively as elsewhere.

Comparing the total area of favorable conditions relative to the number of TCs on any given day illustrates that the seasonal cycle in TC count is also reasonably well captured by the seasonal cycle in total favorable area (Fig. 8a). The mean annual cycle between the global areal extent of favorable conditions and the number of TCs per day is positively correlated, with a Pearson correlation coefficient of 0.696 , but is more strongly correlated when considering individual basins and each hemisphere individually, with a correlation coefficient of 0.935 and 0.811 for $\mathrm{NH}$ and $\mathrm{SH}$, respectively. However, the distribution of environment area is broader than the distribution of TCs; the NH peak TC activity is more concentrated, and in the $\mathrm{SH}$, the number of TCs per day drops to a minimum by June, while the area lags this pattern and does not level out until the month of August. Furthermore, considering the total cumulative area encompassed by favorable conditions annually and the total annual number of observed TCs (Fig. 8b), there is found to be little to no correlation between them globally, for both Northern and Southern Hemispheres, and each individual ocean basin, with the exception of the eastern North Pacific (Table 3).

\section{b. Maximum potential genesis}

Results for MPG using all sizes of contiguous favorability regions (no minimum object area threshold) and a separation distance of $1400 \mathrm{~km}$ are shown in Figs. 9 and 10 . On a daily basis, the areal extent of favorable conditions could hypothetically fit between 42 and 48 TCs simultaneously across the globe (Fig. 9a), should the areas of favorability be densely packed. Daily global estimates peak in the month of September, and closely follow the cycle of environmental area previously shown (Fig. 8a). Similarly, both the NH and SH patterns mimic their annual cycle of areal favorability, with the $\mathrm{NH}$ dominating the global response from May through midDecember. Factoring in the median longevity $(t=$ 6 days), the mean annual global MPG of $\sim 3337$ TCs is the largest among all separation distances and area thresholds (Table 4). All global MPG estimates, ranging from 1212 to 3337 TCs, are an order of magnitude more than the observed mean annual TC count in the current climate. Partitioning results by hemisphere and individual ocean basins, the mean TC climatology (1979-2016) represents $\sim 0.1 \%-17 \%$ of annual MPG estimates, with magnitudes varying by region, area threshold, and separation distance (Table 4). Relative to all basins and hemispheres, the South Atlantic (SATL) ratio is the lowest due to the rarity of TC production within that region (Gray 1968; McTaggart-Cowan et al. 2006). The 
(a)

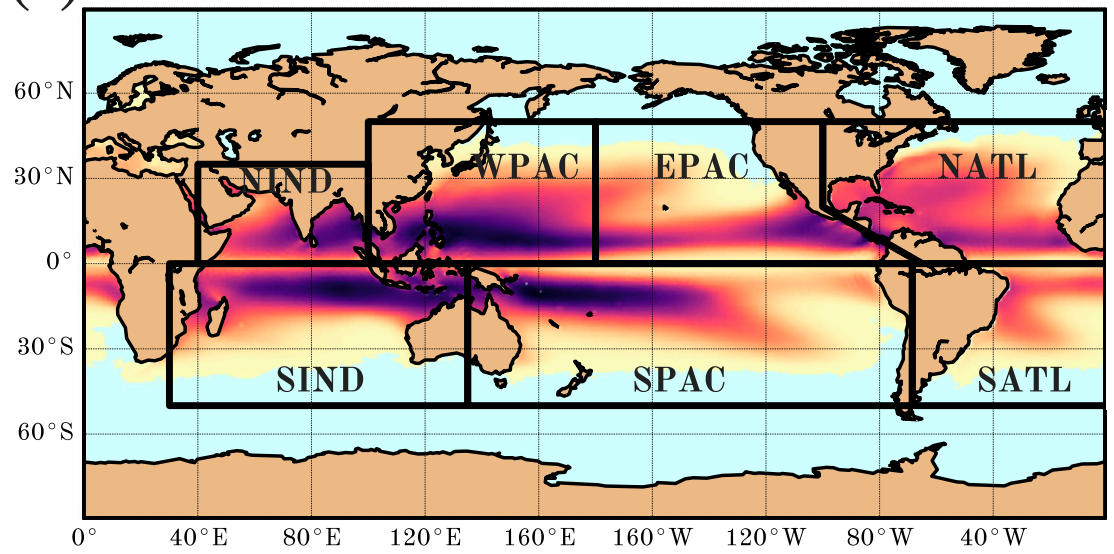

350

300

250

200 先

$150 \stackrel{0}{\circ}$

100

50

0

(b)

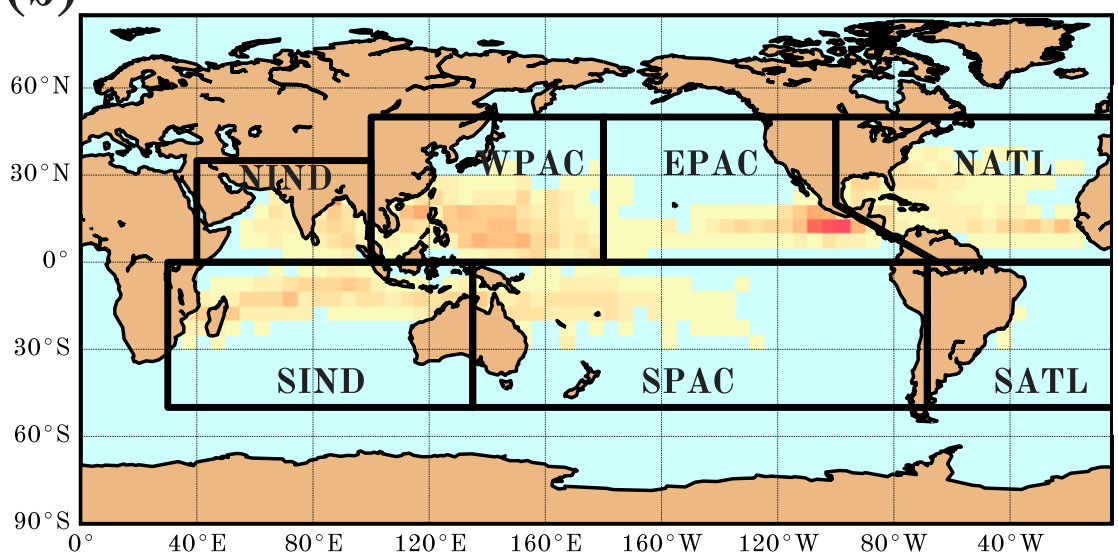

0.0200

0.0175

0.0150

0.0125

0.0100

0.0075

0.0050

0.0025

0.0000

(c)

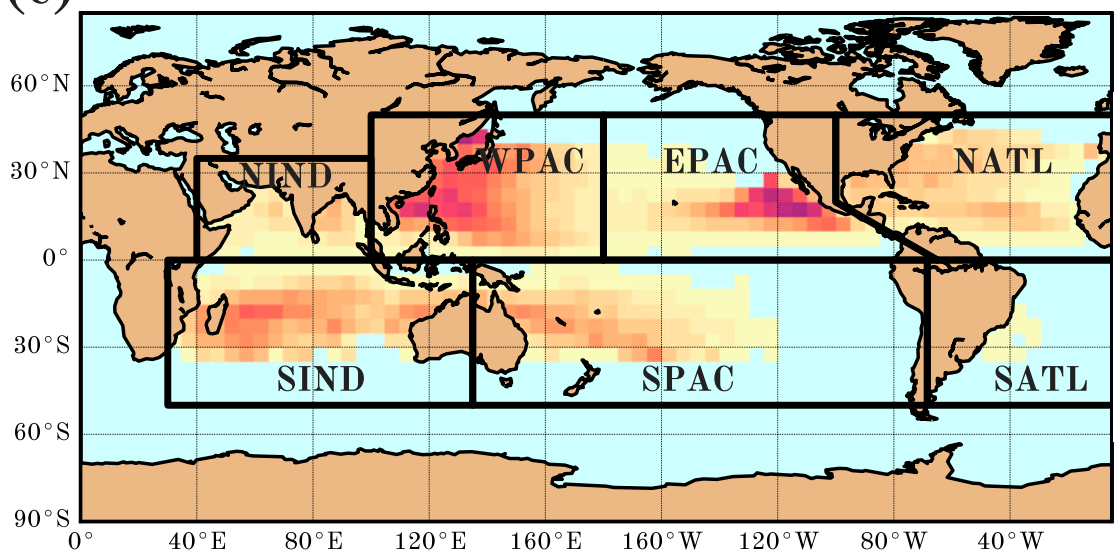

0.10

0.08

0.06 专

0.02

0.00

FIG. 7. Mean annual (a) number of days with conditions favorable for TC genesis and maintenance (VI $<0.145$, $\eta>1.2 \times 10^{-5} \mathrm{~s}^{-1}$, SST $\geq 22^{\circ} \mathrm{C}$ ), (b) mean conditional probability of TC genesis, and (c) mean conditional probability of a TC (at any point in its life cycle) given a favorable environment for the period 1979-2016 from ERA-I. The conditional probability was computed on a coarsened $5^{\circ} \times 5^{\circ}$ latitude-longitude grid to relax the spatial requirement for matches between gridded environmental estimates and TC genesis/track point values. Ocean basins are overlaid on each panel and include the north Indian Ocean (NIND), south Indian Ocean (SIND), western North Pacific (WPAC), South Pacific (SPAC), eastern North Pacific (EPAC), North Atlantic (NATL), and South Atlantic (SATL). 
(a)

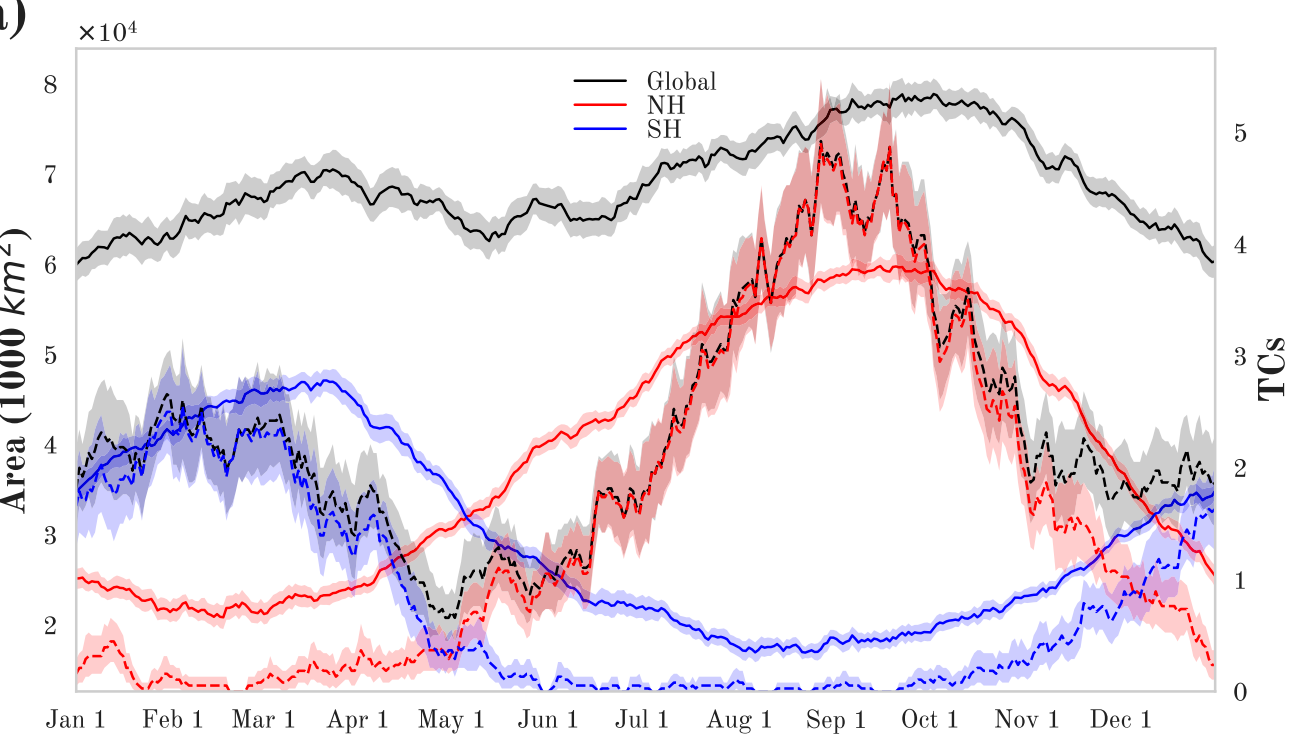

(b)

Date

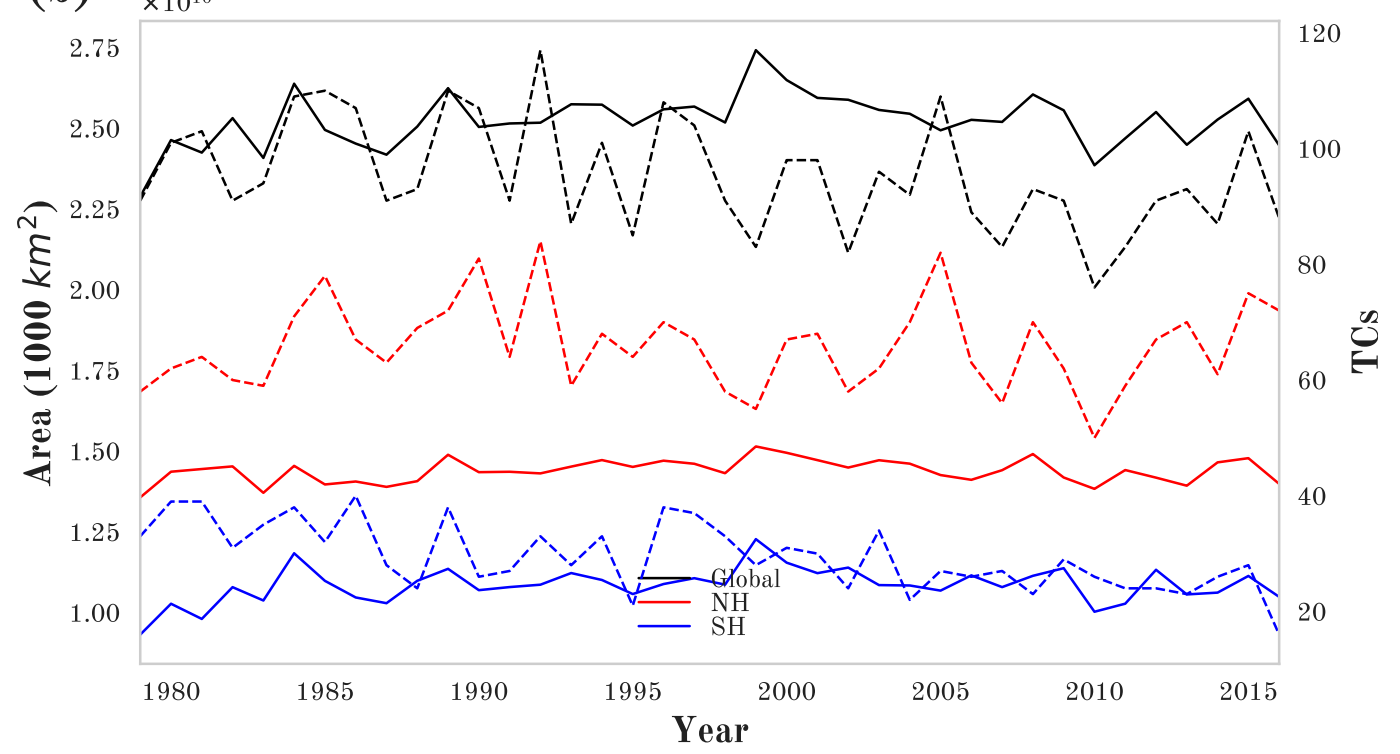

FIG. 8. (a) Total daily area with favorable environmental conditions (solid lines) vs number of TCs per day of year (dashed lines) and (b) the annual cumulative total area and TCs for the Northern Hemisphere, Southern Hemisphere, and globally (solid lines) and annual number of TCs (dashed lines) over the period 1979-2016. Bootstrapped $95 \%$ confidence intervals are shaded in (a).

TC climatology in the western North Pacific (WPAC) accounts for the highest overall proportion of MPG estimates relative to its annual observed TC count $(\sim 6 \%-$ $12 \%)$, exceeded only by the northern Indian Ocean (NIND) for the largest area threshold ( 12\%-17\%). The three NH basins [WPAC, EPAC, North Atlantic (NATL)] are roughly equal contributors to the MPG of the Northern Hemisphere. This may seem counterintuitive at first glance, recognizing that of the three, WPAC experiences favorable environmental conditions more frequently (Fig. 7a). The most frequent areas within WPAC, though, are concentrated in smaller, elongated regions. The storm spacing requirement in our packing procedure suggests that contributions to MPG will be penalized if the frequency of days with favorable conditions are concentrated spatially. Additionally, EPAC and NATL are more elongated zonally, which would favor more storms within this framework.

Notably, interannual variability in total storm count and in global MPG (computed without an area threshold) 
TABLE 3. Pearson correlation values between mean daily and annual cumulative area of environmental favorability and mean daily and annual number of TCs over the 1979-2016 period. Values are computed for global, Northern Hemisphere (NH), Southern Hemisphere (SH), and individual ocean basins, which include the north Indian Ocean (NIND), south Indian Ocean (SIND), western North Pacific (WPAC), South Pacific (SPAC), eastern North Pacific (EPAC), North Atlantic (NATL), and South Atlantic (SATL).

\begin{tabular}{lcc}
\hline \hline & Daily area & Annual cumulative area \\
\hline Global & 0.696 & 0.187 \\
NH & 0.935 & 0.088 \\
SH & 0.811 & 0.025 \\
NIND & 0.482 & -0.155 \\
SIND & 0.795 & 0.136 \\
WPAC & 0.914 & -0.175 \\
SPAC & 0.835 & 0.117 \\
EPAC & 0.920 & 0.559 \\
NATL & 0.817 & 0.377 \\
SATL & 0.324 & -0.110 \\
\hline
\end{tabular}

are both relatively small and the two are poorly correlated with one another (mean Pearson correlation of $\sim 0.2$ for each separation distance). This indicates that interannual variability likely provides relatively little information regarding constraints on MPG. Within individual basins, we find that there is poor correlation for NIND (0.06), south Indian Ocean (SIND) $(-0.2)$, and South Pacific (SPAC) (0.06), moderate negative correlation in the WPAC $(-0.45)$, and positive correlations of 0.3 and 0.4 for EPAC and NATL, respectively. While correlations between MPG and TC count are generally weak, the NATL and EPAC exhibit modest positive correlations, qualitatively consistent with past work finding close statistical relationships between mean environmental conditions and annual counts in the North Atlantic (e.g., Zhao et al. 2009; Murakami et al. 2016). However, recent work (Mei et al. 2019) found in an ensemble of simulations that interannual variability in NATL is poorly explained by mean thermodynamic conditions (10\% explained variance) but more strongly associated with shorter-term fluctuations in weather and intraseasonal variability. Our correlation results are similar to this latter conclusion. Either way, it is also important to emphasize that our work focuses simply on a minimum threshold for environmental variability and does not account for the magnitude of this (a)

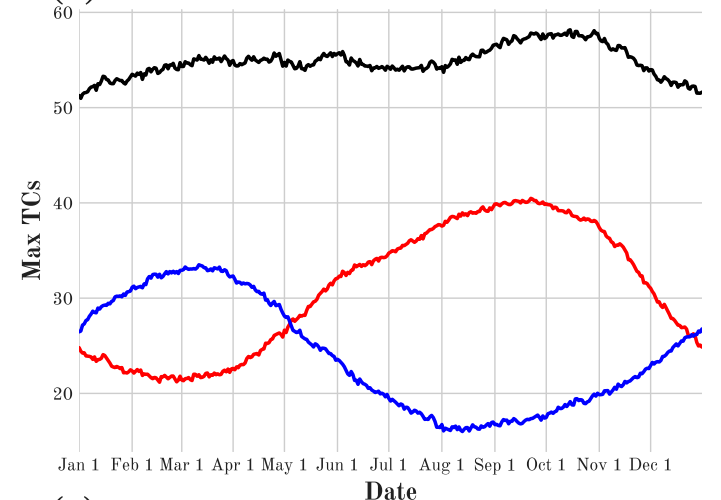

(c)

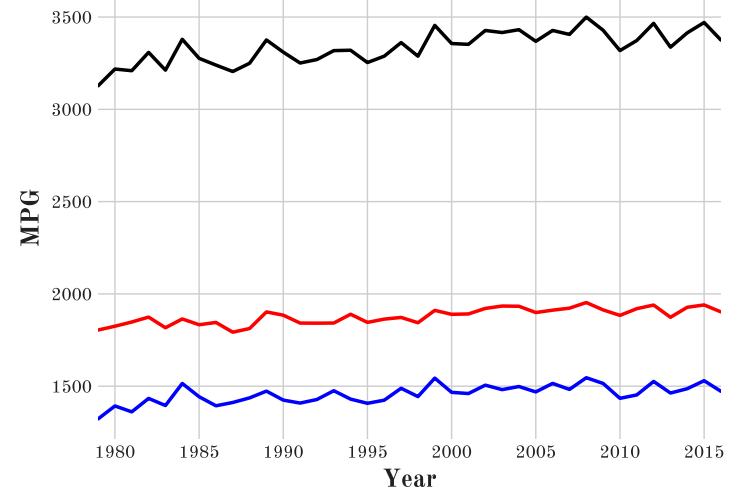

(b)

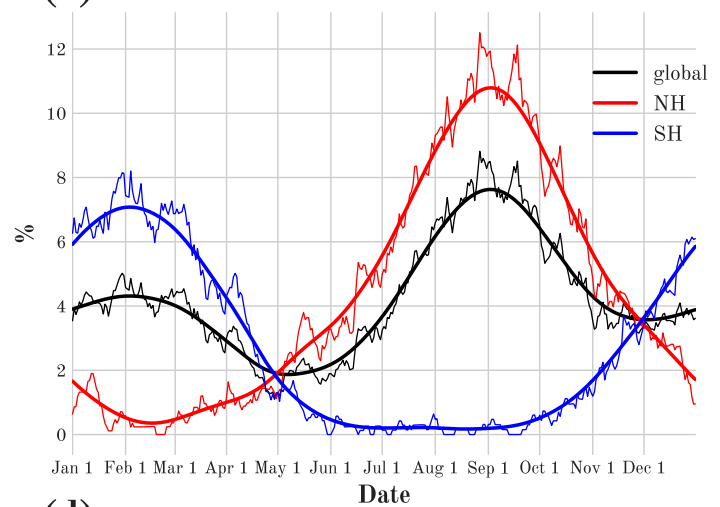

(d)

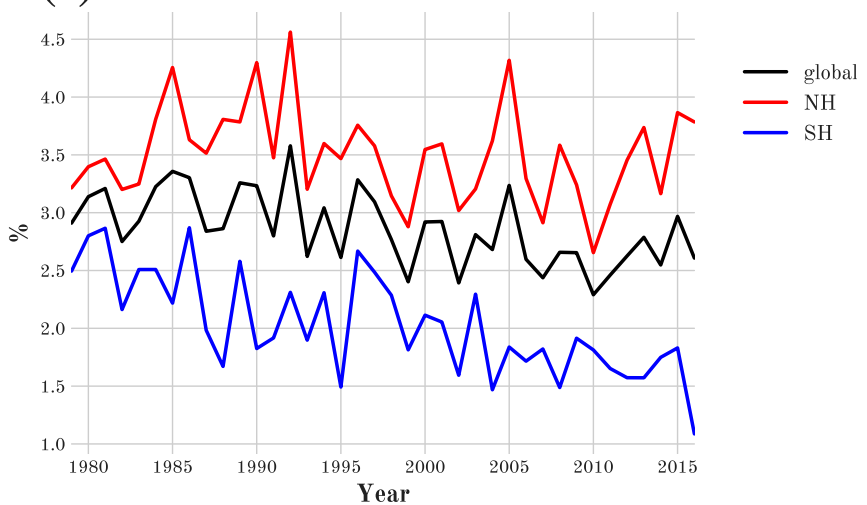

FIG. 9. Estimates for the (a) mean number of randomly placed TCs per day and (b) ratio between observed mean TCs per day to mean daily TC estimates (expressed as a percentage), (c) annual MPG estimates, and (d) ratio of mean annual TC climatology to mean MPG estimates (expressed as a percentage). Results are valid over the period 1979-2016 for the globe and the Southern and Northern Hemispheres, using a separation distance of $1400 \mathrm{~km}$ and without employing a lower bound on the favorable environmental area. A Gaussian filter is applied to (b) with $\sigma=15$ days, denoted by the thicker lines. 
(a)

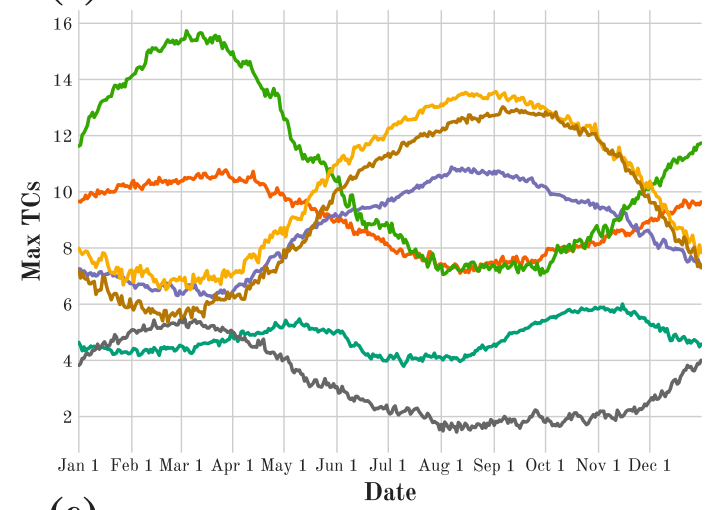

(c)

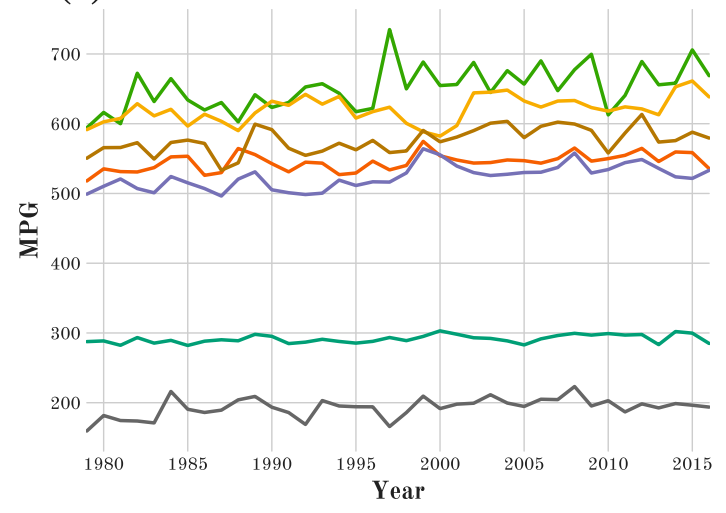

(b)

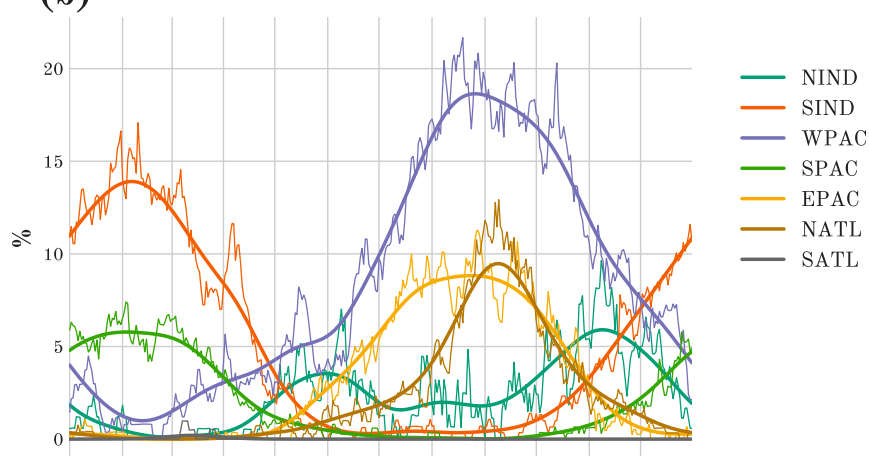

(d)

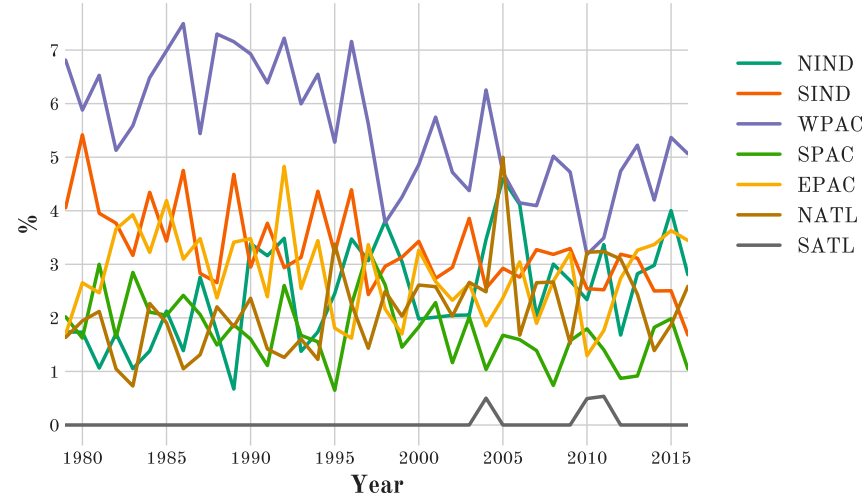

FIG. 10. As in Fig. 9, but for individual ocean basins.

favorability, whose above-threshold variability may yet have impacts on the probability of TC occurrence.

Seasonally, the daily estimates are much closer to TC climatology than the annual MPG would indicate. For example, in Fig. 10b, the daily TC climatology for the WPAC approaches $20 \%$ of the daily estimates in August (nearly $40 \%$ for a separation distance of $2000 \mathrm{~km}$ ). In fact, by examining the distribution of these daily ratios for the entire 1979-2016 period (Fig. 11), relative to all other basins, daily estimates for the WPAC approach observed TC counts much more often. While most days basins are rarely densely packed, the observed TC count does, on occasion, meet or exceed that of the daily estimate by the packing procedure. In general, the annual cycle of the mean daily ratio of the observed TC climatology to daily TC estimates from the packing procedure illustrates that estimates are more robust to observations seasonally, but they far overestimate outside of the respective active TC seasons (i.e., July-October and December-March for $\mathrm{NH}$ and $\mathrm{SH}$, respectively).

As there is a clear seasonal cycle for TCs within the two hemispheres, we may arrive at new MPG estimates by aggregating only the active months from the Northern (JulyOctober) and Southern (December-March) Hemispheres.
By doing so, the annual global MPG estimates for each area threshold and separation distance are reduced by more than half (Table 5). The seasonally subset global MPG still only accounts for $7 \%-16 \%$ of the observed mean annual TC count, though results do vary by basin, with some performing much better than others. For example, the results for the NIND basin utilizing an area threshold of $5.7 \times 10^{6} \mathrm{~km}^{2}$ capture $96 \%$ of the observed JASO climatology when estimated using a separation distance of $2000 \mathrm{~km}$. In general, these results lend further credence that the MPG estimates outside of the main respective TC seasons are significantly inflated. Such an outcome may result from our lack of inclusion of disturbances; however, we do not currently have any information about whether there is significant temporal variability in the disturbances themselves, and thus this hypothesis is left as a suggested avenue for future work.

The sensitivity to increasing separation distance simply reduces the MPG without modifying the interannual pattern (Fig. 12). In fact, Pearson correlation values between distances are greater than 0.999 for each of the three different area thresholds used to compute MPG estimates. Similarly, the effect of increasing area threshold reduces the annual MPG (Tables 4 and 5), with the 


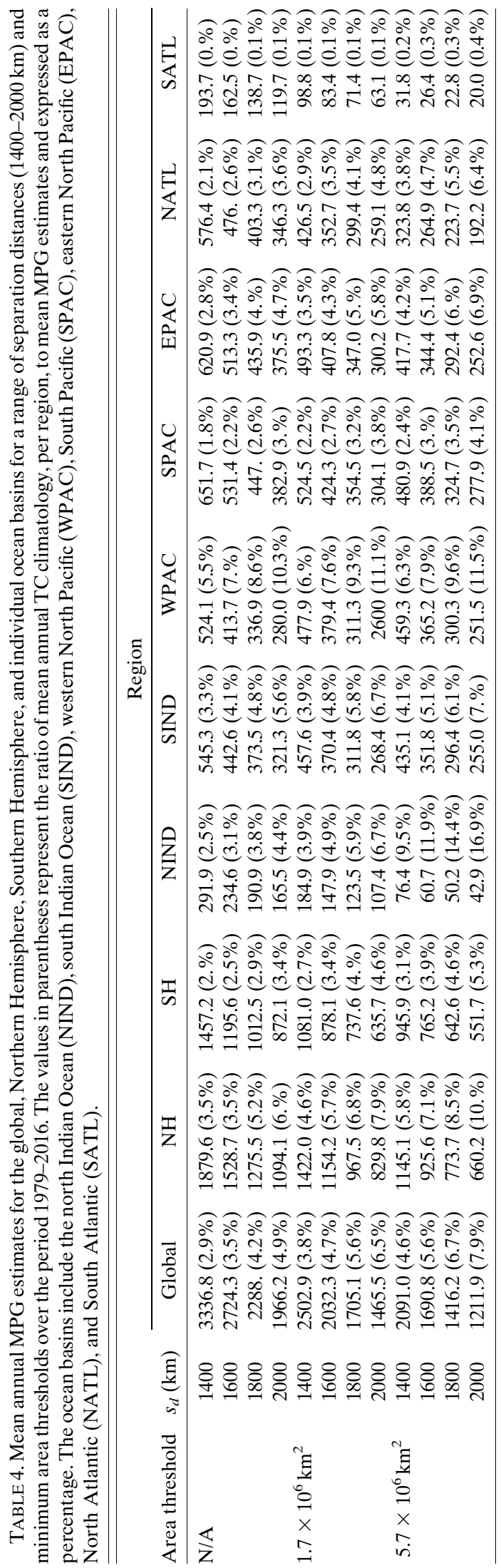

largest changes noted between the use of no area threshold and the maximum area threshold considered, as would be anticipated. Overall, environmental favorability generally captures the seasonal cycle variability, but the annual MPG estimates are an order of magnitude larger than observations.

A limitation of using the daily data is that we do not take into account duration of the favorable conditions, and as such, the necessity of using higher temporal frequency data may be questioned. We investigate whether the use of daily temporal frequency data influences the magnitude of MPG relative to use of a monthly mean area of favorability. We utilize monthly mean VI, $\eta$, and SST to identify the regions. For simplicity, we apply the same thresholds for each quantity to define regions of favorable conditions and apply the same area thresholds. the method to arrive at MPG is modified slightly to accommodate the lower frequency data. First, the packing procedure fills the monthly mean area, the same as is done for an individual day. The resulting number of TCs that are packed in the monthly delineated environment is then multiplied by the number of days within the month. From there, all months are summed and normalized by the median TC duration [as in Eq. (3)] to arrive at a new annual MPG. The use of a monthly mean implies a longer duration of favorable environmental conditions than the daily temporal data. Results for this modified methodology relative to results from daily frequency data are found in Table 6 . The approaches differ relatively little, $\sim 15 \%-16 \%,<6 \%$, and $<1.5 \%$ for all areas and the two increasing area thresholds, respectively. For these choices of thresholds, use of monthly data appears not to impact results much, and has the added benefit of being more computationally efficient.

\section{Summary and discussion}

To investigate what controls the global rate of TC formation, we tested a simple hypothesis that the annual TC count is limited by the geography of thermodynamic environments favorable for TC formation and maintenance. Environmental favorability was defined using empirically defined thresholds for the ventilation index and $850-\mathrm{hPa}$ absolute vorticity. First, we found that the areal extent of favorable environmental conditions does well in capturing the seasonal evolution of the observed climatological TC activity. Specifically, the seasonal cycle of area of environmental favorability corresponds well to the seasonal cycle of TCs globally, a relationship that is more pronounced when separated by hemisphere (Fig. 8). Observed TC activity within these regions varies in time and especially in space, an indication that 

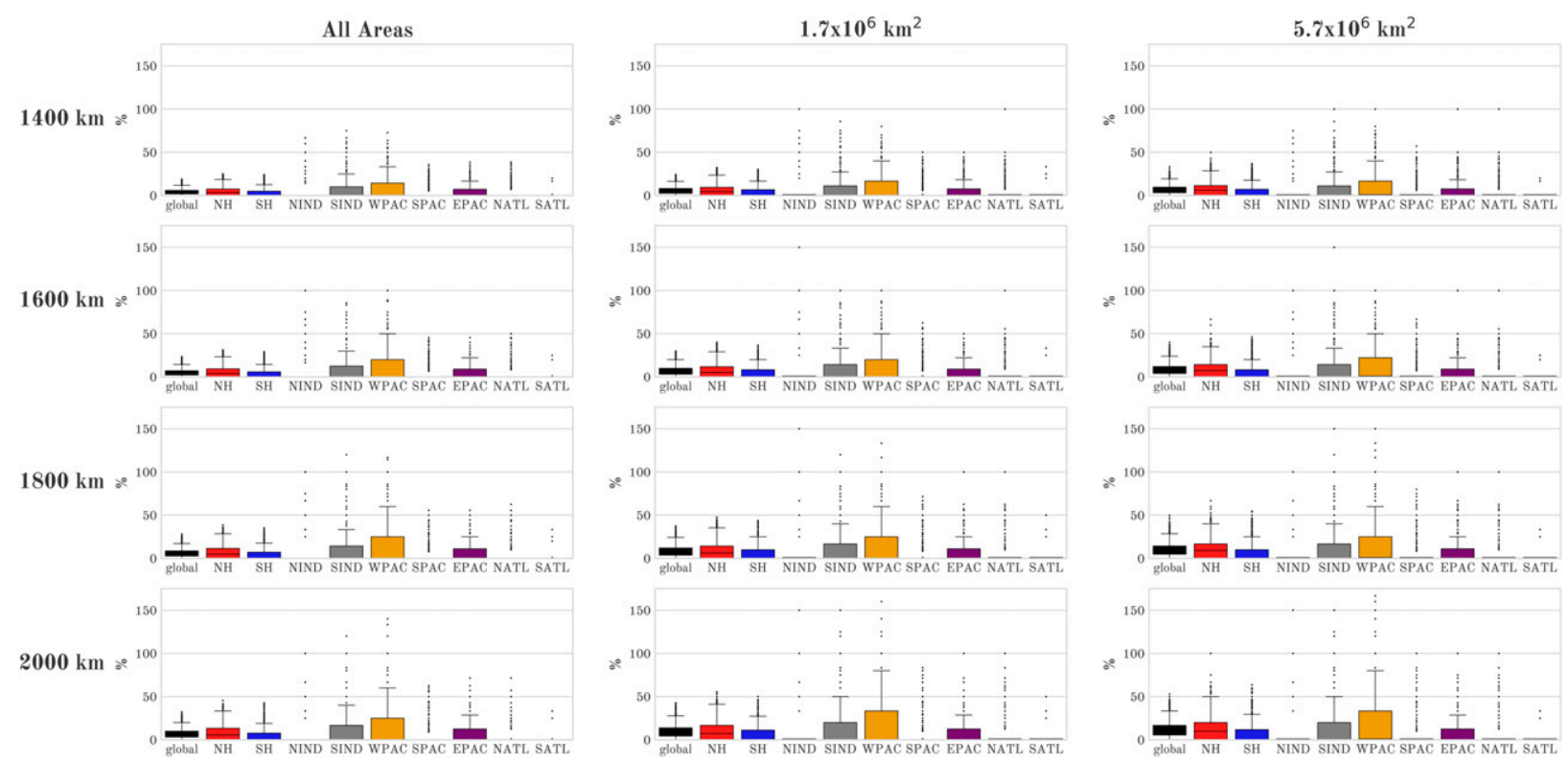

FIG. 11. Distributions of the ratio of observed TCs to daily maximum TC estimates (expressed a percentage) for the global, NH, SH, and ocean basin estimates for each separation distance and environment object area threshold. Distributions incorporate all days in the 19792016 period.

TCs frequently do not exist despite otherwise supportive environmental conditions (as defined here). This is not surprising, as the environmental estimates lack the explicit inclusion of a precursor disturbance that may result in TC formation, and may further be missing additional regional dynamical or thermodynamic feedbacks not currently accounted for.

Based on the spatiotemporal distribution of favorable environmental conditions, we then developed a simple method for estimating the maximum annual number of possible TCs, termed maximum potential genesis (MPG), derived from densely packing randomly placed TCs within regions of daily favorability, using separation distances motivated by observed length scales of storm interaction and separation in nature. The daily estimates are summed for the year and subsequently normalized by the median duration of time TCs historically exist within favorable environments during their life cycle. The results for MPG, computed using a range of separation distances between 1400 and $2000 \mathrm{~km}$ with and without the inclusion of a minimum area threshold for contiguous regions of favorability, suggest that the geography of favorable environments could hypothetically support an order of magnitude greater number of TCs than are currently found in the present-day Earth climate. Results by calendar day, while still an overestimate of TC activity, closely mimic the seasonal TC climatology when partitioned by hemisphere and ocean basin. It is the overprediction within the respective off-seasons that most strongly contributes to the annual global MPG overestimates. Increasing the separation distance reduces the estimated MPG rather uniformly, and decreasing the area threshold reduces the MPG magnitudes, but does not qualitatively alter the conclusions. Furthermore, we demonstrated that the sensitivity to the use of monthly mean environmental conditions relative to daily temporal frequency was negligible for our set of parameters and thresholds.

The imposition of an SST constraint, although conservative at our choice of $22^{\circ} \mathrm{C}$, may be considered undesirable, as previously acknowledged. Analysis without the incorporation of a modest SST (not shown) significantly inflated estimates of global MPG relative to our presented results, even after excluding smaller regions of favorability. This result is likely due to transient favorable environments at high latitudes poleward of the traditional geographic domain of tropical cyclone identification, which may be associated with favorable for subtropical and polar lows (Emanuel and Rotunno 1989).

The increasing trend in annual global MPG, as seen in Figs. 9a and 12a is not evident in the annual accumulated area (Fig. 8b) nor the results when the minimum object area thresholds are introduced (Figs. 12b,c), suggestive that the trend arises from an increase in smaller areas of favorability. To investigate further, we find evidence of statistically significant trends in the annual number of days with favorable conditions (Fig. A1 in the appendix) indicative of a poleward migration in environmental 


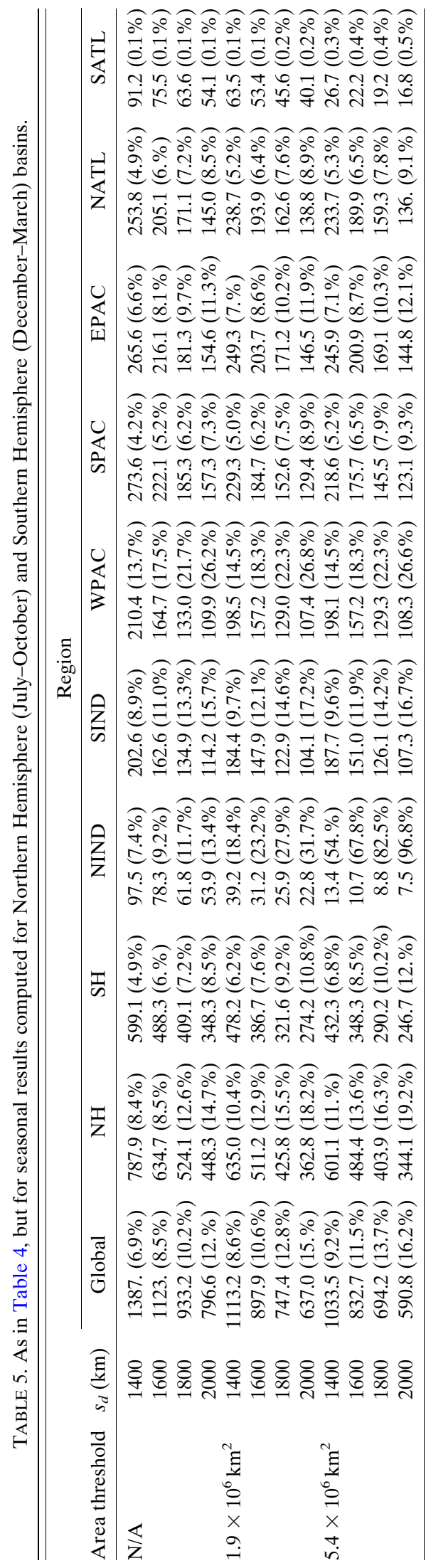

favorability. In some of these areas, significant increasing trends are on the order of 30 or more days decade ${ }^{-1}$. This finding is consistent with Daloz and Camargo (2018) that values of GPI parameters (e.g., wind shear, $u_{\mathrm{PI}}$, entropy deficit) and GPIs themselves are becoming more favorable in poleward regions, and appears correlated with both the poleward migration of TC lifetime maximum intensity (Kossin et al. 2014) and TC genesis over most of the Pacific (Daloz and Camargo 2018).

What factors bridge the gap between our MPG estimate and the real annual TC count in the present-day Earth climate? This gap may represent both deficiencies in our simple methodology that can be improved in future work as well as real physical factors for why the annual TC count is limited from reaching its potential. Here we discuss possible factors in the context of our MPG framework:

1) Separation distance: Actual separation distances are typically larger than the Fujiwhara length scale and are likely tied to the physical processes that generate the disturbances that develop into TCs, such as African easterly waves (AEWs) and ITCZ breakdown, and the role of large-scale equatorial modes of variability, such as the MJO. Additionally, we currently neglect any temporal displacement between storm formation that is common to multiple tropical cyclone events (e.g., Schenkel 2016, 2017).

2) Conditional genesis probabilities: Here we have defined regions above a minimum threshold for favorability without consideration of the magnitude of our favorability parameter within these regions. However, given the inherent stochasticity associated with genesis, it may be important to consider accounting probabilistically for genesis conditioned on the magnitude of both the thermodynamic factors (ventilation index) and dynamic factors (Chavas and Reed 2019).

3) Additional environmental factors may be at play, such as the role of large-scale ascent (Held and Zhao 2011; Zhou et al. 2019), that are not accounted for in common existing genesis indices.

4) Minimum area threshold: How small of an area of favorable conditions is required, and for how long a duration, to permit the genesis of a storm? This is an unanswered question, but it is relevant specifically to the question of genesis counts, particularly in geographically confined basins such as the north Indian Ocean.

5) Storm duration: Here we have crudely assumed a simple constant median storm duration within favorable regions, but this varies in space and time and may impact storm counts, particularly on interannual time scales. 

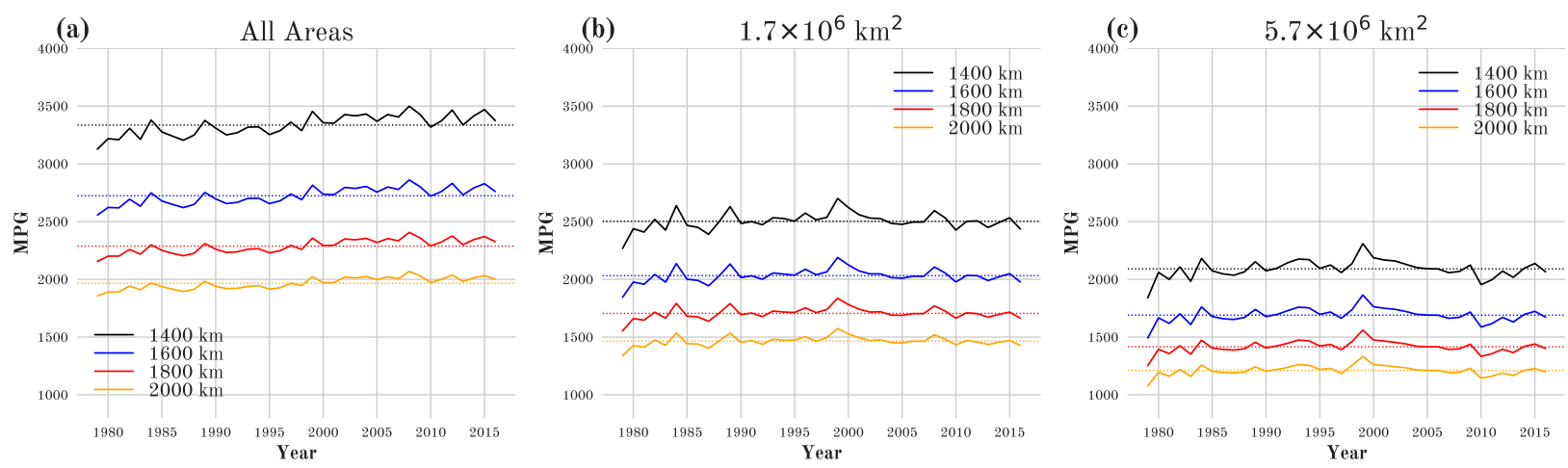

FIG. 12. Estimates for annual MPG for (a) all environment objects, (b) environment objects exceeding $1.7 \times 10^{6} \mathrm{~km}{ }^{2}$ in area, and (c) environment objects exceeding $5.7 \times 10^{6} \mathrm{~km}^{2}$ for each of the four separation distances used. Results are valid over the period 1979-2016.

6) Precursor disturbances: The geography of preexisting disturbances is not accounted for at all in our approach and has generally received more limited attention given that it lacks the simplicity of analyzing larger-scale environmental parameters. However, the relative geographies of precursor disturbances and environmental favorability may provide further insight into mismatches between the spatiotemporal variabilities of MPG and actual TC count.

Overall, this work provides a novel quantitative test for the hypothesis that global TC count is constrained by the geography of environmental favorability, which may be considered the simplest physical hypothesis to this open question. There remain numerous ways in which this method may be further modified, including adapting the procedure to account for variability in both the physical and temporal separation distance between synthetic genesis locations and the specified TC duration

TABLE 6. Mean annual global MPG estimates using daily and monthly mean data. The relative difference between the two estimates is displayed as a percentage. Mean values are valid over the period 1979-2016.

\begin{tabular}{|c|c|c|c|c|}
\hline \multirow[b]{2}{*}{ Area threshold } & \multirow[b]{2}{*}{$s_{d}(\mathrm{~km})$} & \multicolumn{2}{|c|}{ Global MPG } & \multirow[b]{2}{*}{$\%$ Difference } \\
\hline & & Daily & Monthly & \\
\hline \multirow[t]{4}{*}{ N/A } & 1400 & 3336.83 & 2838.84 & 14.92 \\
\hline & 1600 & 2724.33 & 2276.54 & 16.44 \\
\hline & 1800 & 2288.01 & 1911.92 & 16.44 \\
\hline & 2000 & 1966.23 & 1651.15 & 16.02 \\
\hline \multirow[t]{4}{*}{$1.7 \times 10^{6} \mathrm{~km}^{2}$} & 1400 & 2473.45 & 2327.62 & 5.90 \\
\hline & 1600 & 2006.9 & 1889.3 & 5.86 \\
\hline & 1800 & 1685.55 & 1592.05 & 5.55 \\
\hline & 2000 & 1446.74 & 1373.69 & 5.05 \\
\hline \multirow[t]{4}{*}{$5.7 \times 10^{6} \mathrm{~km}^{2}$} & 1400 & 2116.51 & 2086.07 & 1.44 \\
\hline & 1600 & 1711.63 & 1686.67 & 1.46 \\
\hline & 1800 & 1434.03 & 1418.18 & 1.11 \\
\hline & 2000 & 1227.24 & 1219.54 & 0.63 \\
\hline
\end{tabular}

within MPG, accounting for the spatiotemporal distribution of precursor disturbances, and the incorporation of novel physical parameters or processes that account for potential feedbacks between storms and between a storm and the large-scale environment, both atmosphere and upper ocean, and on both short and long time scales. Future work could also explore how MPG, and measures of thermodynamic favorability in general, work if applied in a simplified aquaplanet world like in Chavas and Reed (2019), whose boundary forcing is thermodynamically ideal. Merlis et al. (2016) used this aquaplanet approach and found a strong dependence of genesis count on temperature, which could be due to changes in favorability or perhaps changes in storm size and spacing. Clearly, there are some very basic questions about genesis that we do not currently understand, and applying the techniques used in this paper to simplified worlds might be very fruitful. Additionally, a physical understanding of what controls the marked spatial variability of TC production within favorable environments, as well as the lower rate of production of storms outside of peak seasons in each hemisphere, would likely go a long way toward filling the gap between our pure thermodynamic estimate of maximum potential genesis presented here and the observed annual genesis rate. Finally, we note that this methodology may be applied to alternative climate states, both past and future. We hope that this work will provide a foundation for such deeper analyses in pursuit of a broader theory for what sets the annual global TC count on Earth.

Acknowledgments. We thank Tom Philp for first positing the concept of maximum potential genesis. Additionally, the authors thank Tim Merlis, Greg Holland, and an anonymous reviewer for their thorough and insightful comments and suggestions on this work, which substantially improved the manuscript. 


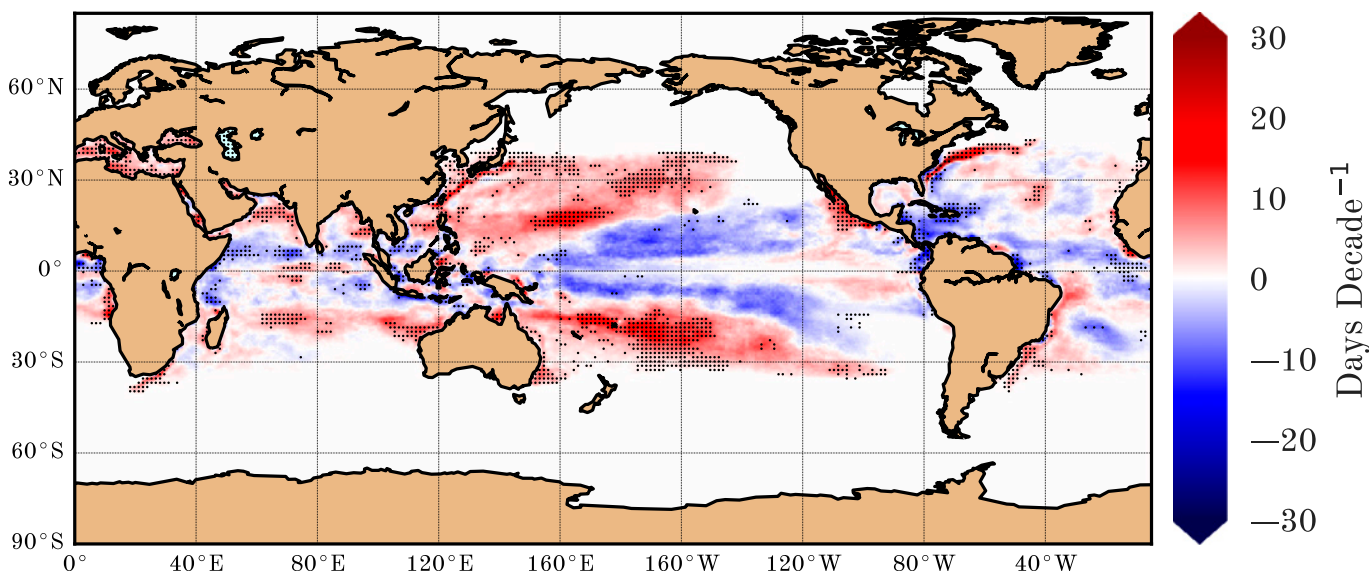

FIG. A1. The trend (days decade ${ }^{-1}$ ) in annual number of days with environmental favorability. Stippling represents areas where the trend is statistically significant at the 95\% level. Trends were computed for the period 1979-2016.

\section{APPENDIX}

\section{Spatial Trends in Environmental Favorability}

The spatial trends in the annual number of days (per decade) of environmental favorability (1979-2016) is assessed using the Theil-Sen estimator (e.g., Sen 1968) to at each grid point (Fig. A1). Statistical significance at the $95 \%$ confidence level is assessed using Kendall's tau (Kendall 1938).

\section{REFERENCES}

Bister, M., and K. A. Emanuel, 2002: Low frequency variability of tropical cyclone potential intensity 1 . Interannual to interdecadal variability. J. Geophys. Res., 107, 4801, https://doi.org/ 10.1029/2001JD000776.

Bony, S., and Coauthors, 2015: Clouds, circulation and climate sensitivity. Nat. Geosci., 8, 261-268, https://doi.org/10.1038/ ngeo2398.

Brand, S., 1970: Interaction of binary tropical cyclones of the western North Pacific Ocean. J. Appl. Meteor., 9, 433-441, https://doi.org/10.1175/1520-0450(1970)009<0433: IOBTCO $>2.0 . \mathrm{CO} ; 2$.

Bruyère, C. L., G. J. Holland, and E. Towler, 2012: Investigating the use of a genesis potential index for tropical cyclones in the North Atlantic basin. J. Climate, 25, 8611-8626, https://doi.org/ 10.1175/JCLI-D-11-00619.1.

Camargo, S. J., and A. A. Wing, 2016: Tropical cyclones in climate models. Wiley Interdiscip. Rev.: Climate Change, 7, 211-237, https://doi.org/10.1002/wcc.373.

— A. H. Sobel, A. G. Barnston, and K. A. Emanuel, 2007a: Tropical cyclone genesis potential index in climate models. Tellus, 59A, 428-443, https://doi.org/10.1111/J.1600-0870.2007.00238.X.

_ K. A. Emanuel, and A. H. Sobel, 2007b: Use of a genesis potential index to diagnose ENSO effects on tropical cyclone genesis. J. Climate, 20, 4819-4834, https://doi.org/10.1175/ JCLI4282.1.

— M. C. Wheeler, and A. H. Sobel, 2009: Diagnosis of the MJO modulation of tropical cyclogenesis using an empirical index. J. Atmos. Sci., 66, 3061-3074, https://doi.org/10.1175/2009JAS3101.1.
—, M. K. Tippett, A. H. Sobel, G. A. Vecchi, and M. Zhao, 2014: Testing the performance of tropical cyclone genesis indices in future climates using the HiRAM model. J. Climate, 27, 91719196, https://doi.org/10.1175/JCLI-D-13-00505.1.

Caron, L.-P., and C. G. Jones, 2008: Analysing present, past and future tropical cyclone activity as inferred from an ensemble of coupled global climate models. Tellus, $\mathbf{6 0 A}, 80-96$, https:// doi.org/10.1111/J.1600-0870.2007.00291.X.

Chauvin, F., and J.-F. Royer, 2010: Role of the SST anomaly structures in response of cyclogenesis to global warming. Hurricanes and Climate Change, J. Elsner et al., Eds., Vol. 2, Springer, 39-56, https://doi.org/10.1007/978-90-481-9510-7.

Chavas, D. R., 2017: A simple derivation of tropical cyclone ventilation theory and its application to capped surface entropy fluxes. J. Atmos. Sci., 74, 2989-2996, https://doi.org/10.1175/ JAS-D-17-0061.1.

— , and K. A. Reed, 2019: Dynamical aquaplanet experiments with uniform thermal forcing: System dynamics and implications for tropical cyclone genesis and size. J. Atmos. Sci., 76, 2257-2274, https://doi.org/10.1175/JAS-D-19-0001.1.

Daloz, A. S., and S. J. Camargo, 2018: Is the poleward migration of tropical cyclone maximum intensity associated with a poleward migration of tropical cyclone genesis? Climate Dyn., 50, 705-715, https://doi.org/10.1007/s00382-017-3636-7.

Dee, D. P., and Coauthors, 2011: The ERA-Interim reanalysis: Configuration and performance of the data assimilation system. Quart. J. Roy. Meteor. Soc., 137, 553-597, https://doi.org/ 10.1002/qj.828.

Defforge, C. L., and T. M. Merlis, 2017: Evaluating the evidence of a global sea surface temperature threshold for tropical cyclone genesis. J. Climate, 30, 9133-9145, https://doi.org/10.1175/ JCLI-D-16-0737.1.

DeMaria, M., J. A. Knaff, and B. H. Connell, 2001: A tropical cyclone genesis parameter for the tropical Atlantic. Wea. Forecasting, 16, 219-233, https://doi.org/10.1175/1520-0434(2001) 016<0219:ATCGPF $>2.0 . C O ; 2$.

ECMWF, 2009: Era-Interim project. NCAR Research Data Archive, accessed 13 July 2017, https://doi.org/10.5065/D6CR5RD9.

Emanuel, K., 2010: Tropical cyclone activity downscaled from NOAA-CIRES reanalysis, 1908-1958. J. Adv. Model. Earth Syst., 2 (1), https://doi.org/10.3894/JAMES.2010.2.1. 
_ 2012: Self-stratification of tropical cyclone outflow. Part II: Implications for storm intensification. J. Atmos. Sci., 69, 988996, https://doi.org/10.1175/JAS-D-11-0177.1.

— , and R. Rotunno, 1989: Polar lows as Arctic hurricanes. Tellus, 41, 1-17, https://doi.org/10.3402/tellusa.v41i1.11817. , and D. Nolan, 2004: Tropical cyclone activity and the global climate system. 26th Conf. on Hurricanes and Tropical Meteorology, Miami, FL, Amer. Meteor. Soc., 10A.2, https:// ams.confex.com/ams/26HURR/techprogram/paper_75463.htm.

R. Sundararajan, and J. Williams, 2008: Hurricanes and global warming: Results from downscaling IPCC AR4 simulations. Bull. Amer. Meteor. Soc., 89, 347-368, https://doi.org/ 10.1175/BAMS-89-3-347.

Ferreira, R. N., and W. H. Schubert, 1997: Barotropic aspects of ITCZ breakdown. J. Atmos. Sci., 54, 261-285, https://doi.org/ 10.1175/1520-0469(1997)054<0261:BAOIB >2.0.CO;2.

Frank, W. M., and P. E. Roundy, 2006: The role of tropical waves in tropical cyclogenesis. Mon. Wea. Rev., 134, 2397-2417, https:// doi.org/10.1175/MWR3204.1.

Fujiwhara, S., 1921: The natural tendency towards symmetry of motion and its application as a principle in meteorology. Quart. J. Roy. Meteor. Soc., 47, 287-292, https://doi.org/ 10.1002/qj.49704720010.

Gao, J., and T. Li, 2011: Factors controlling multiple tropical cyclone events in the western North Pacific. Mon. Wea. Rev., 139, 885-894, https://doi.org/10.1175/2010MWR3340.1.

Gray, W. M., 1968: Global view of the origin of tropical disturbances and storms. Mon. Wea. Rev., 96, 669-700, https://doi.org/ 10.1175/1520-0493(1968)096<0669:GVOTOO >2.0.CO;2.

_ 1979: Hurricanes: Their formation, structure and likely role in the tropical circulation. Meteorology over the Tropical Oceans, D. B. Shaw, Ed., Royal Meteorological Society, 155218.

Hart, R. E., R. N. Maue, and M. C. Watson, 2007: Estimating local memory of tropical cyclones through MPI anomaly evolution. Mon. Wea. Rev., 135, 3990-4005, https://doi.org/ 10.1175/2007MWR2038.1.

Held, I. M., and M. Zhao, 2011: The response of tropical cyclone statistics to an increase in $\mathrm{CO}_{2}$ with fixed sea surface temperatures. J. Climate, 24, 5353-5364, https://doi.org/10.1175/ JCLI-D-11-00050.1.

Holland, G. J., 1995: Scale interaction in the western Pacific monsoon. Meteor. Atmos. Phys., 56, 57-79, https://doi.org/ 10.1007/BF01022521.

_ 1997: The maximum potential intensity of tropical cyclones. J. Atmos. Sci., 54, 2519-2541, https://doi.org/10.1175/15200469(1997)054<2519:TMPIOT > 2.0.CO;2.

Johnson, N. C., and S.-P. Xie, 2010: Changes in the sea surface temperature threshold for tropical convection. Nat. Geosci., 3, 842-845, https://doi.org/10.1038/ngeo1008.

Kaplan, J., M. DeMaria, and J. A. Knaff, 2010: A revised tropical cyclone rapid intensification index for the Atlantic and eastern North Pacific basins. Wea. Forecasting, 25, 220-241, https:// doi.org/10.1175/2009WAF2222280.1.

Kendall, M. G., 1938: A new measure of rank correlation. Biometrika, 30, 81-93, https://doi.org/10.1093/biomet/30.1-2.81.

Khairoutdinov, M. F., and K. Emanuel, 2010: Aggregated convection and the regulation of tropical climate. 29th Conf. on Hurricanes and Tropical Meteorology, Tucson, AZ, Amer. Meteor. Soc., P2.69, https://ams.confex.com/ams/29Hurricanes/techprogram/paper_ 168418.htm.

Kim, J.-H., S. J. Brown, and R. E. McDonald, 2011: Future changes in tropical cyclone genesis in fully dynamic ocean- and mixed layer ocean-coupled climate models: A low-resolution model study. Climate Dyn., 37, 737-758, https://doi.org/10.1007/ s00382-010-0855-6.

Klotzbach, P. J., and E. C. J. Oliver, 2015: Modulation of Atlantic basin tropical cyclone activity by the Madden-Julian oscillation (MJO) from 1905 to 2011. J. Climate, 28, 204-217, https:// doi.org/10.1175/JCLI-D-14-00509.1.

Knapp, K. R., M. C. Kruk, D. H. Levinson, H. J. Diamond, and C. J. Neumann, 2010: The International Best Track Archive for Climate Stewardship (IBTrACS). Bull. Amer. Meteor. Soc., 91, 363-376, https://doi.org/10.1175/2009BAMS2755.1.

Knutson, T., and Coauthors, 2019: Tropical cyclones and climate change assessment: Part II. Projected response to anthropogenic warming. Bull. Amer. Meteor. Soc., https://doi.org/ 10.1175/BAMS-D-18-0194.1, in press.

Korty, R. L., K. A. Emanuel, M. Huber, and R. A. Zamora, 2017: Tropical cyclones downscaled from simulations with very high carbon dioxide levels. J. Climate, 30, 649-667, https://doi.org/ 10.1175/JCLI-D-16-0256.1.

Kossin, J. P., K. A. Emanuel, and G. A. Vecchi, 2014: The poleward migration of the location of tropical cyclone maximum intensity. Nature, 509, 349-352, https://doi.org/10.1038/nature13278.

Krouse, K. D., and A. H. Sobel, 2010: An observational study of multiple tropical cyclone events in the western North Pacific. Tellus, 62A, 256-265, https://doi.org/10.1111/j.16000870.2010.00435.x.

Li, R. C. Y., W. Zhou, J. C. L. Chan, and P. Huang, 2012: Asymmetric modulation of western North Pacific cyclogenesis by the MaddenJulian oscillation under ENSO conditions. J. Climate, 25, 5374 5385, https://doi.org/10.1175/JCLI-D-11-00337.1.

Mann, H. B., and D. R. Whitney, 1947: On a test of whether one of two random variables is stochastically larger than the other. Ann. Math. Stat., 18, 50-60, https://doi.org/10.1214/aoms/1177730491.

McGauley, M. G., and D. S. Nolan, 2011: Measuring environmental favorability for tropical cyclogenesis by statistical analysis of threshold parameters. J. Climate, 24, 5968-5997, https:// doi.org/10.1175/2011JCLI4176.1.

McTaggart-Cowan, R., L. F. Bosart, C. A. Davis, E. H. Atallah, J. R. Gyakum, and K. A. Emanuel, 2006: Analysis of Hurricane Catarina (2004). Mon. Wea. Rev., 134, 3029-3053, https://doi.org/10.1175/MWR3330.1.

, E. L. Davies, J. G. Fairman, T. J. Galarneau, and D. M. Schultz, 2015: Revisiting the $26.5^{\circ} \mathrm{C}$ sea surface temperature threshold for tropical cyclone development. Bull. Amer. Meteor. Soc., 96, 1929-1943, https://doi.org/10.1175/BAMS-D13-00254.1.

Mei, W., Y. Kamae, S.-P. Xie, and K. Yoshida, 2019: Variability and predictability of North Atlantic hurricane frequency in a large ensemble of high-resolution atmospheric simulations. $J$. Climate, 32, 3153-3167, https://doi.org/10.1175/JCLI-D-18-0554.1.

Menkes, C. E., M. Lengaigne, P. Marchesiello, N. C. Jourdain, E. M. Vincent, J. Lefèvre, F. Chauvin, and J.-F. Royer, 2012: Comparison of tropical cyclogenesis indices on seasonal to interannual timescales. Climate Dyn., 38, 301-321, https:// doi.org/10.1007/s00382-011-1126-x.

Merlis, T. M., W. Zhou, I. M. Held, and M. Zhao, 2016: Surface temperature dependence of tropical cyclone-permitting simulations in a spherical model with uniform thermal forcing. Geophys. Res. Lett., 43, 2859-2865, https://doi.org/10.1002/2016GL067730.

Murakami, H., and B. Wang, 2010: Future change of North Atlantic tropical cyclone tracks: Projection by a $20-\mathrm{km}-\mathrm{mesh}$ global atmospheric model. J. Climate, 23, 2699-2721, https:// doi.org/10.1175/2010JCLI3338.1. 
G. Villarini, G. A. Vecchi, W. Zhang, and R. Gudgel, 2016: Statistical-dynamical seasonal forecast of North Atlantic and U.S. landfalling tropical cyclones using the high-resolution GFDL FLOR coupled model. Mon. Wea. Rev., 144, 21012123, https://doi.org/10.1175/MWR-D-15-0308.1.

Ramsay, H., 2017: The global climatology of tropical cyclones. Natural Hazard Science, Oxford University Press, https:// doi.org/10.1093/acrefore/9780199389407.013.79.

Royer, J.-F., F. Chauvin, B. Timbal, P. Araspin, and D. Grimal, 1998: A GCM study of the impact of greenhouse gas increase on the frequency of occurrence of tropical cyclones. Climatic Change, 38, 307-343, https://doi.org/10.1023/A:1005386312622.

Schenkel, B. A., 2016: A climatology of multiple tropical cyclone events. J. Climate, 29, 4861-4883, https://doi.org/10.1175/JCLI-D-15-0048.1.

_ 2017: Are multiple tropical cyclone events similar among basins? J. Climate, 30, 5805-5813, https://doi.org/10.1175/JCLI-D-17-0088.1. , and R. E. Hart, 2015: An analysis of the environmental moisture impacts of western North Pacific tropical cyclones. J. Climate, 28, 2600-2622, https://doi.org/10.1175/JCLI-D-14-00213.1.

Schreck, C. J., III, K. R. Knapp, and J. P. Kossin, 2014: The impact of best track discrepancies on global tropical cyclone climatologies using IBTrACS. Mon. Wea. Rev., 142, 3881-3899, https://doi.org/10.1175/MWR-D-14-00021.1.

Sen, P. K., 1968: Estimates of the regression coefficient based on Kendall's tau. J. Amer. Stat. Assoc., 63, 1379-1389, https:// doi.org/10.1080/01621459.1968.10480934.

Song, Y., L. Wang, X. Lei, and X. Wang, 2015: Tropical cyclone genesis potential index over the western North Pacific simulated by CMIP5 models. Adv. Atmos. Sci., 32, 1539-1550, https://doi.org/10.1007/s00376-015-4162-3.

Tang, B., and K. Emanuel, 2012: A ventilation index for tropical cyclones. Bull. Amer. Meteor. Soc., 93, 1901-1912, https:// doi.org/10.1175/BAMS-D-11-00165.1.

_ - and S. J. Camargo, 2014: Environmental control of tropical cyclones in CMIP5: A ventilation perspective. J. Adv. Model. Earth Syst., 6, 115-128, https://doi.org/10.1002/2013MS000294.

Thorncroft, C., and K. Hodges, 2001: African easterly wave variability and its relationship to Atlantic tropical cyclone activity. J. Climate, 14, 1166-1179, https://doi.org/10.1175/1520-0442(2001) 014<1166:AEWVAI > 2.0.CO;2.

Tippett, M. K., S. J. Camargo, and A. H. Sobel, 2011: A Poisson regression index for tropical cyclone genesis and the role of large-scale vorticity in genesis. J. Climate, 24, 2335-2357, https://doi.org/10.1175/2010JCLI3811.1.

Tory, K. J., and R. A. Dare, 2015: Sea surface temperature thresholds for tropical cyclone formation. J. Climate, 28, 81718183, https://doi.org/10.1175/JCLI-D-14-00637.1.
H. Ye, and R. A. Dare, 2018: Understanding the geographic distribution of tropical cyclone formation for applications in climate models. Climate Dyn., 50, 2489-2512, https://doi.org/ 10.1007/s00382-017-3752-4.

Vecchi, G. A., and B. J. Soden, 2007: Increased tropical Atlantic wind shear in model projections of global warming. Geophys. Res. Lett., 34, L08702, https://doi.org/10.1029/2006GL028905.

Vincent, E. M., K. A. Emanuel, M. Lengaigne, J. Vialard, and G. Madec, 2014: Influence of upper ocean stratification interannual variability on tropical cyclones. J. Adv. Model. Earth Syst., 6, 680-699, https://doi.org/10.1002/2014MS000327.

Walsh, K. J., and Coauthors, 2016: Tropical cyclones and climate change. Wiley Interdiscip. Rev.: Climate Change, 7, 65-89, https://doi.org/10.1002/wcc.371.

Wang, B., and J.-Y. Moon, 2017: An anomalous genesis potential index for MJO modulation of tropical cyclones. J. Climate, $\mathbf{3 0}$, 4021-4035, https://doi.org/10.1175/JCLI-D-16-0749.1.

Wheeler, M., and G. N. Kiladis, 1999: Convectively coupled equatorial waves: Analysis of clouds and temperature in the wavenumberfrequency domain. J. Atmos. Sci., 56, 374-399, https://doi.org/ 10.1175/1520-0469(1999)056<0374:CCEWAO > 2.0.CO;2.

Wing, A. A., and K. A. Emanuel, 2014: Physical mechanisms controlling self-aggregation of convection in idealized numerical modeling simulations. J. Adv. Model. Earth Syst., 6, 59-74, https://doi.org/10.1002/2013MS000269.

Wu, L., and M. Takahashi, 2018: Contributions of tropical waves to tropical cyclone genesis over the western North Pacific. Climate Dyn., 50, 4635-4649, https://doi.org/10.1007/s00382017-3895-3.

Yokoi, S., and Y. N. Takayabu, 2009: Multi-model projection of global warming impact on tropical cyclone genesis frequency over the western North Pacific. J. Meteor. Soc. Japan, 87, 525538, https://doi.org/10.2151/jmsj.87.525.

Yokota, S., H. Niino, and W. Yanase, 2015: Tropical cyclogenesis due to ITCZ breakdown: Idealized numerical experiments and a case study of the event in July 1988. J. Atmos. Sci., 72, 3663-3684, https://doi.org/10.1175/JAS-D-14-0328.1.

Zhao, M., I. M. Held, S.-J. Lin, and G. A. Vecchi, 2009: Simulations of global hurricane climatology, interannual variability, and response to global warming using a $50-\mathrm{km}$ resolution GCM. J. Climate, 22, 6653-6678, https://doi.org/ 10.1175/2009JCLI3049.1.

Zhou, W., M. Zhao, and D. Yang, 2019: Understand the direct effect of $\mathrm{CO}_{2}$ increase on tropical circulation and TC activity: Land surface warming versus direct radiative forcing. Geophys. Res. Lett., 46, 6859-6867, https://doi.org/10.1029/ 2019 GL082865. 